\title{
FOCAL INFECTIONS FROM CHRONIC SINUSITIS
}

\author{
(Experimental studies)
}

\author{
By \\ T. NÚNOMURA
}

\section{From the Department of Oto-Rhino-Larygology, Tokwshima Unitowsity School of Meatitine (Director: Prof. G. Skivalares)}

The experimental enimals used in this study were rabbits. Chronic sinusitis was produced in the animals by infusing bacteria and egg-white albumin into the parananal sinus over long periodi of time. These phlogistic substances were atao injected into the blood to produce pathologic conditions in the heart and kidney. Subsequent observations on the above phenomena have led to thefollowing conclusions:

1) Infusion of bacteria into the peranasal sinus of rabbits over long period of time resulto: in cardiac and renal dysfunction. The dysfunctions occur in a higher incidence and severity in sensitized groups than in unsensitized groups. In proportion to the this, the agglutination test of serum for bacteria is positive. Histological study of the mucous membrane of the paramasa] sinus shows allergic reaction and also inflammetory reaction.

2) Repeated Injection of egg-white albumin into the parasasal sinus over long period of timeproduces cardiac and renal dysfunction like thase mentioned alove. The pathologic changes are similar to those which follow to the repeated infusion of egg-white albumin into the blood orex a. period of time. The mucous membrane of the paranasal sinus shown allergic tissue reaction.

3) In the cases with cardiac complications, the electrocardiograms show depressed ST regment in most of the cages. Low and flat $\mathrm{T}$ waves are occasionally seen. Histologically, myocarditis interstitialis is noted together with myocarditis parenchymetose. The electrocardiographic finding. and the bistologic picture are approximately in parallel relationship with each other.

4) In the kidney, dysfunction mostly develops in glomeruli and renal tubules. Appearance of albumin in urine is consistent with the dysfunction. Histological study shows glomerulonephritia. accompanied by nephritis tubularis. Results of renal function test are approximately in parallei. relationship with the histological findings.

5) Injection of bacteria into the blood over long period of time results in cerdiac and renal disturbances similar to those mentioned above. Myocarditis interstitialis and nephritis tubularis attributed to the direct injury by bacterial toxin are produced, and myocarditis parenchymatose and glomezulonephritis attributed to allergic mechanism are also produced. The agglutination tẹt of serum for bacteria is at first negative but later becomes positive.

6) During the cardiac and renal disturbences secondary to bacterial sinusitis, no bacteria could. be demonstrated in the heart or kidney. Killed bacteria injected into tho blood induced the identical disturbances with those induced by the injection of viable bacteria. This fact suggests that in focal infection what is absorbed is not bacteria themselves bat their toxin.

7) The bacterial toxin so absorbed is presumed to directly injure the heert and kidney on one: hand, and on the other hand to become allergen for allergic reaction, thus damaging tissues.

8) In the histological pictures of the heart and kidney, the pathologic changes are relatively mild and do not seem to be irreversible. This fully explains the clinical experience that secondary diseases to focal infection are reversible by removing the primary focus. 


\section{慢性副鼻㓐类に上る病巣感染 \\ (实 融 的 研 究)}

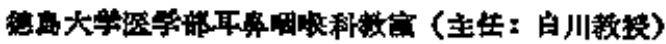

軬梦利先

1.

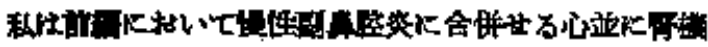

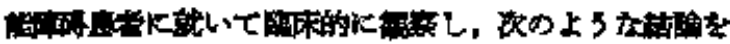
得车.

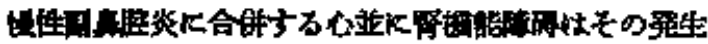

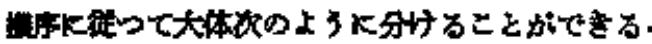

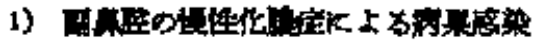

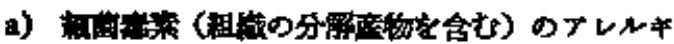

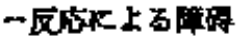

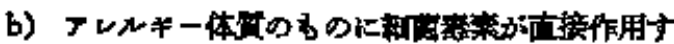

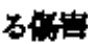

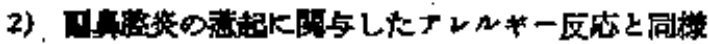

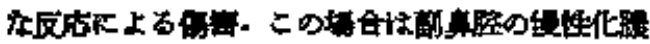

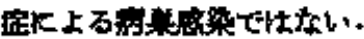

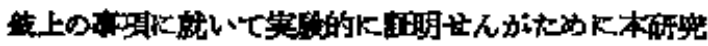

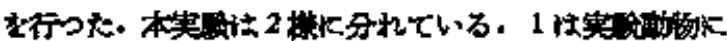

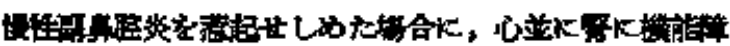

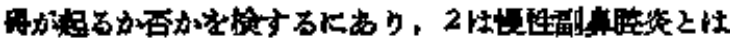

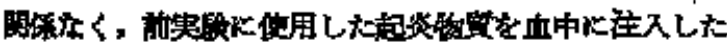

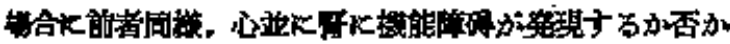

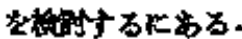

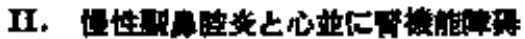

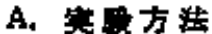

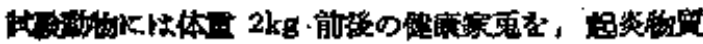

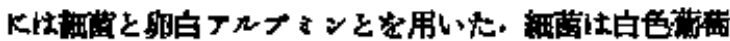

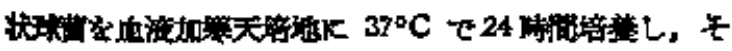

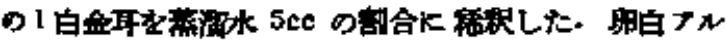

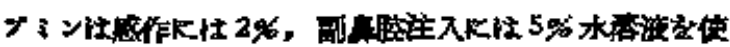

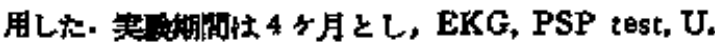

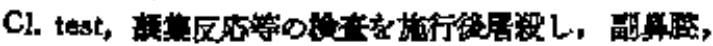

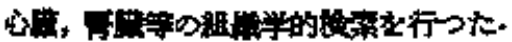

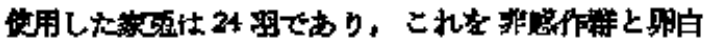

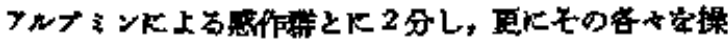

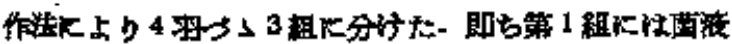

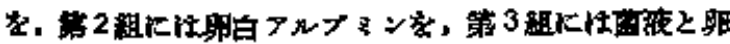

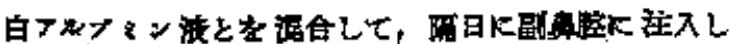

た.

\section{B. 実的成葴}

1)的床虚状

a) 菲感作单

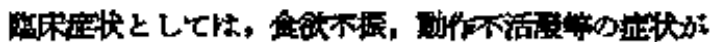

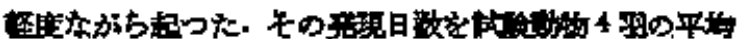

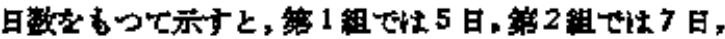

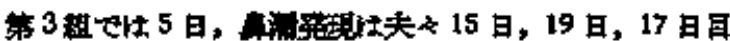

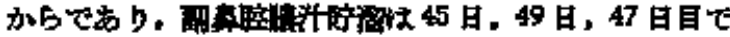

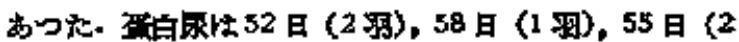

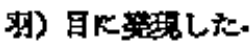

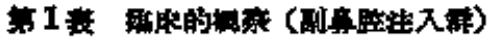

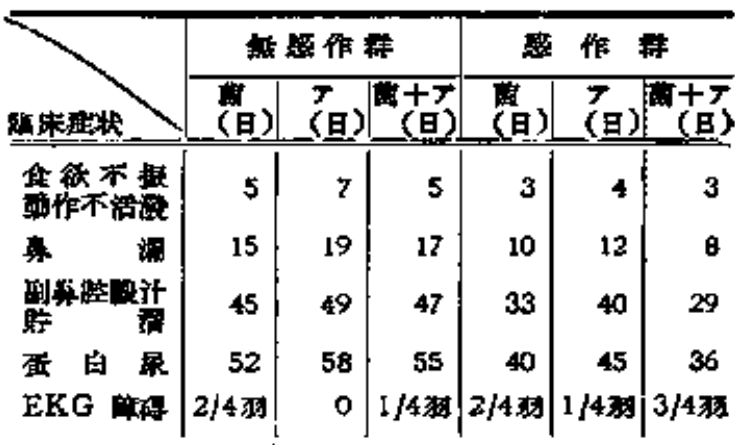

b) 密作藉

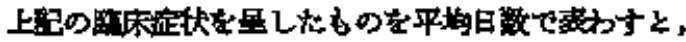

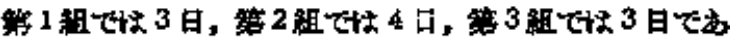

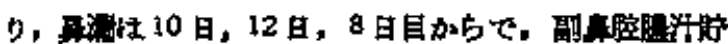

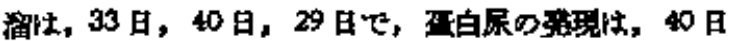

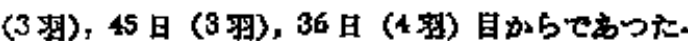

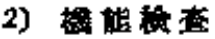

a) EKG 部所㒻

i) 非感作群

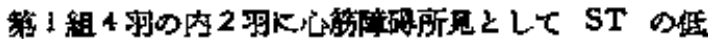

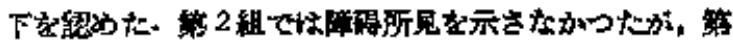

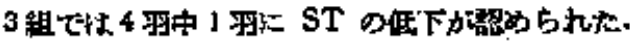

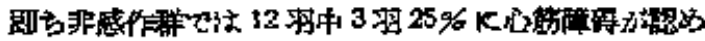
られた。 


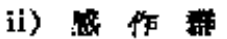

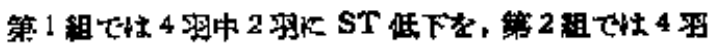

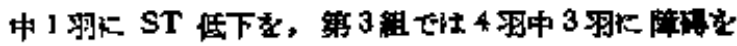

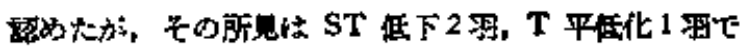

らつた.

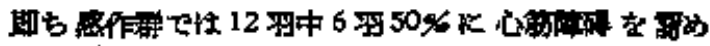
たー

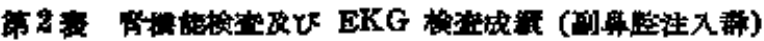

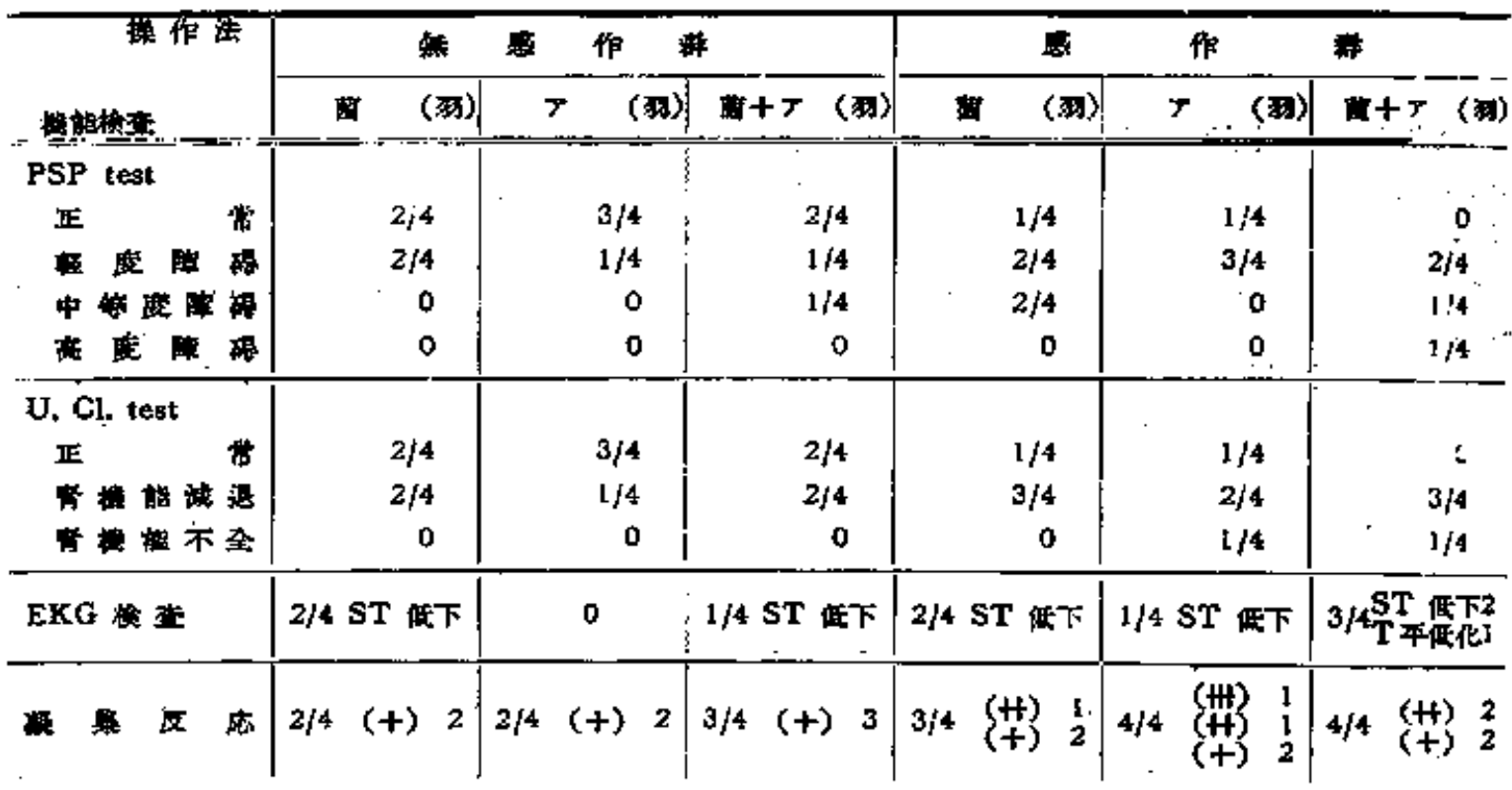

b) PSP test o所基

i) 非感作漌

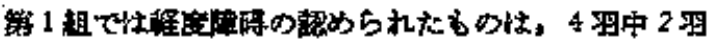

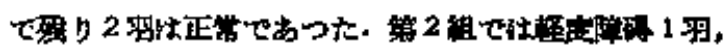

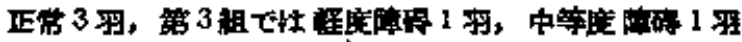

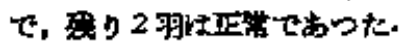

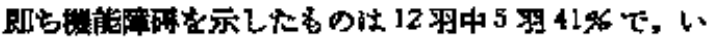

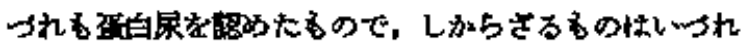
正常で离つた。

\section{ii) 艁作}

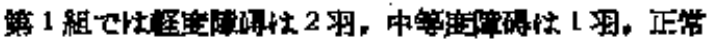

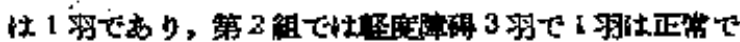

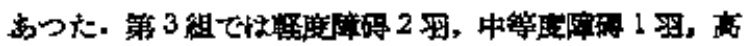

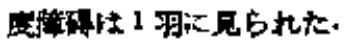

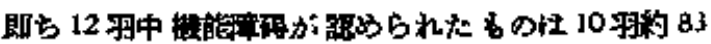

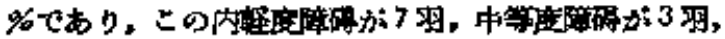

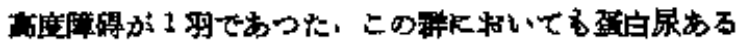

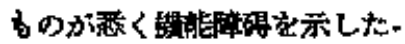

c) U. Cl. test $\omega$ 形见

i) 菲感作禁

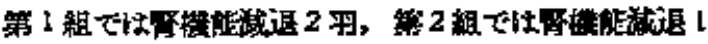

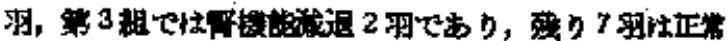
と判定された。

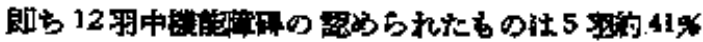

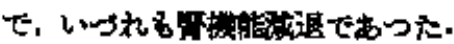

ii) 作 碚

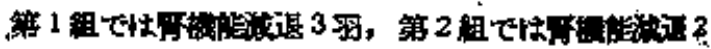

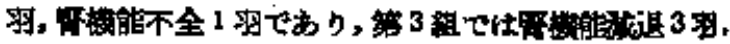

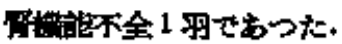

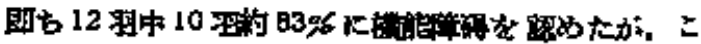

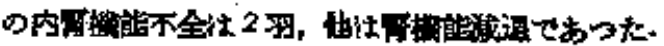

3) 酦䉾反心

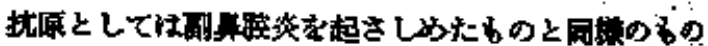

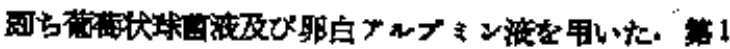

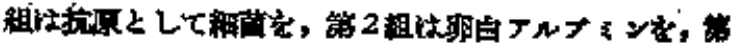

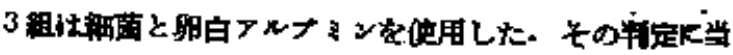

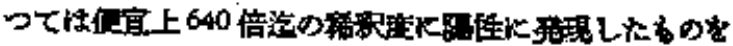

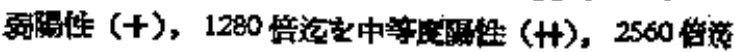
を倠侽姓 (卅) とした.

a) 非感作研

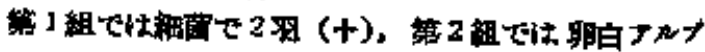

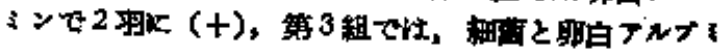


ンで环に (十)に登现した.

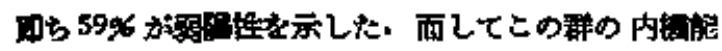

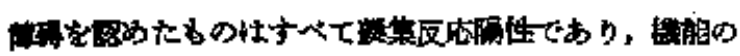

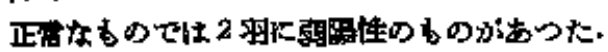

b) 作群

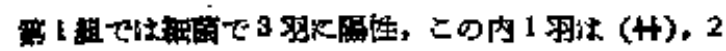

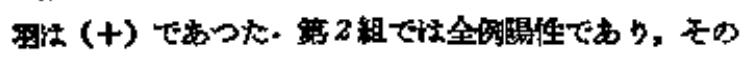

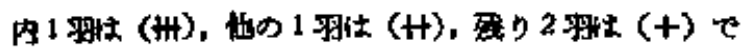

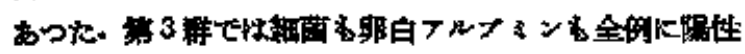

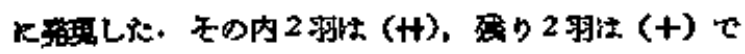
bった.

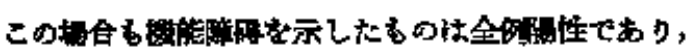

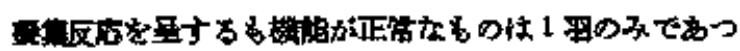

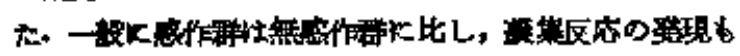

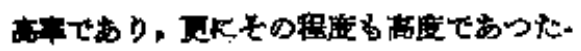

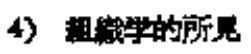

a) 耶 卧

i) 非感作群

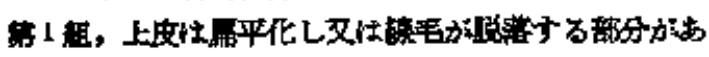

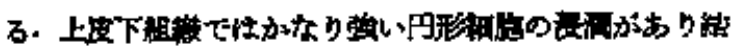

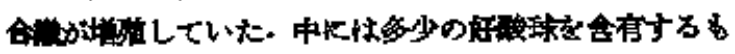

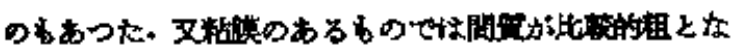

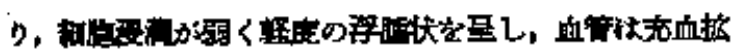

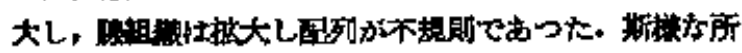

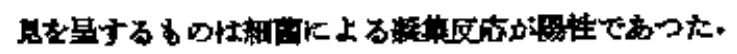

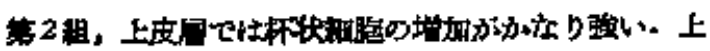

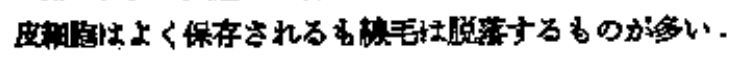

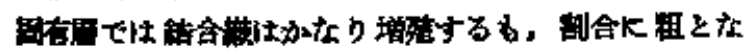

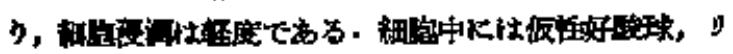

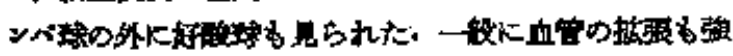

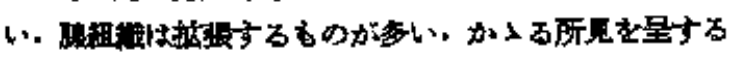

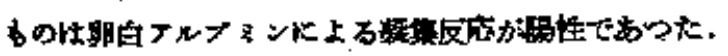

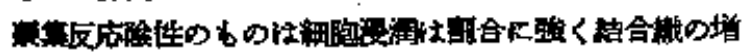

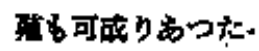

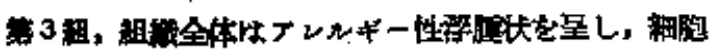

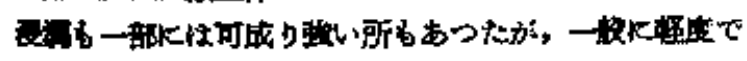

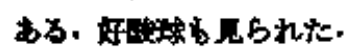

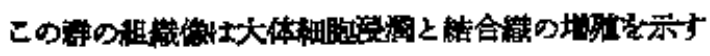

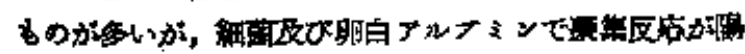

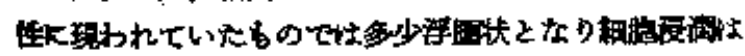

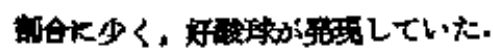

ii) 作 儌

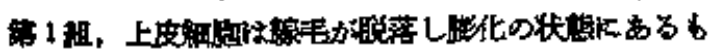

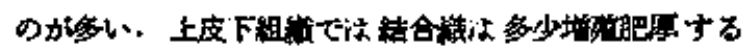

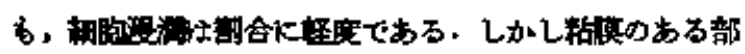

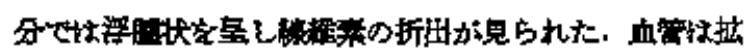

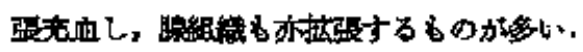

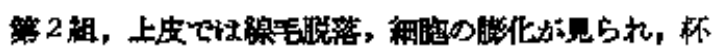

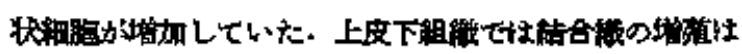

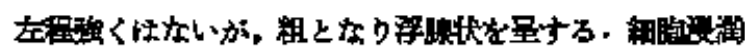

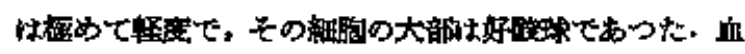

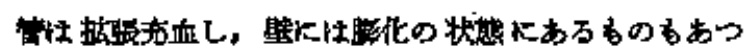

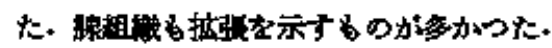

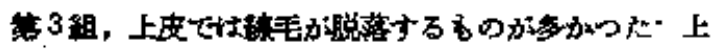

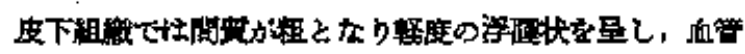

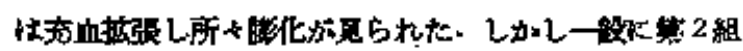

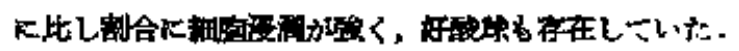

\section{b) 心}

i) 非蛒作群

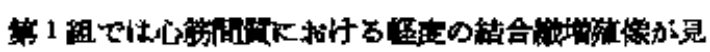

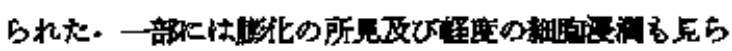

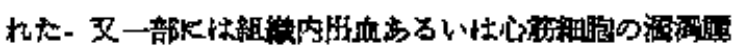

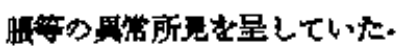

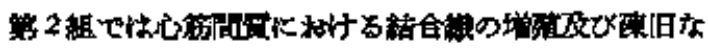

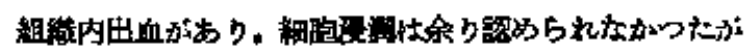

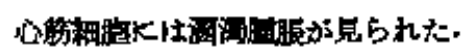

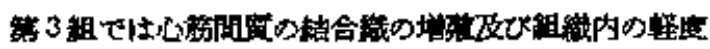

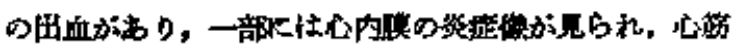

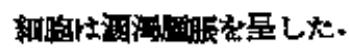

ij) 感作

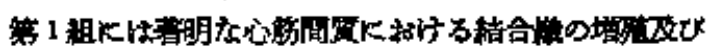

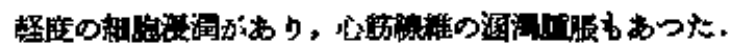

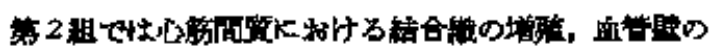

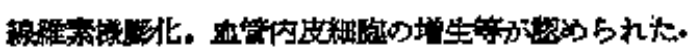

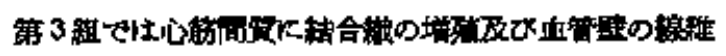

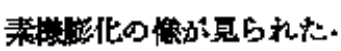

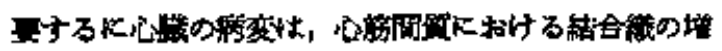

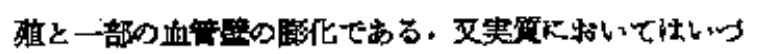

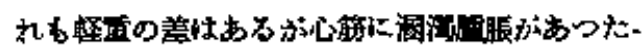

c) 管

i) 非忠作翻

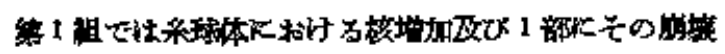

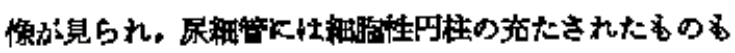

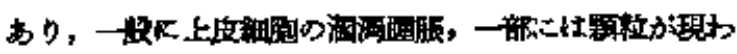
れ強い变性ををたしているるのるあった。

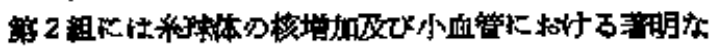




\begin{tabular}{|c|c|c|c|c|c|c|c|c|c|c|c|}
\hline & & \multicolumn{2}{|c|}{0} & \multicolumn{3}{|c|}{ N } & \multicolumn{2}{|c|}{8} & & 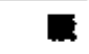 & \\
\hline 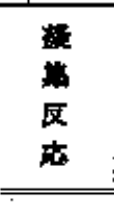 & & 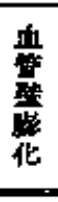 & $\begin{array}{l}\text { 点 } \\
\text { 行 } \\
\text { 借 } \\
\text { 业 }\end{array}$ & 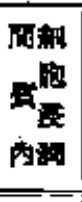 & 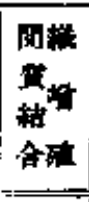 & 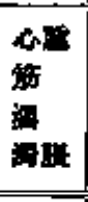 & 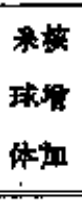 & \begin{tabular}{c}
\multirow{2}{*}{$\mathbf{j}$} \\
$\mathbf{T}$ \\
出 \\
血
\end{tabular} & 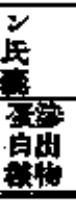 & 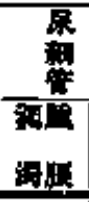 & $\frac{p^{2}}{2}$ \\
\hline 四性 & 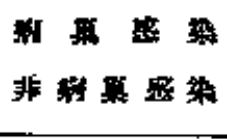 & $\begin{array}{l}H \\
+\end{array}$ & $\begin{array}{l}+ \\
+\end{array}$ & $\begin{array}{l}H \\
-\end{array}$ & $\begin{array}{l}H \\
-\end{array}$ & $\begin{array}{l}+ \\
+\end{array}$ & $\begin{array}{l}H \\
\pm\end{array}$ & $\begin{array}{l}+ \\
+\end{array}$ & $\begin{array}{l}\boldsymbol{r} \\
-\end{array}$ & $\begin{array}{l}+ \\
+\end{array}$ & $\begin{array}{l}+ \\
-\end{array}$ \\
\hline 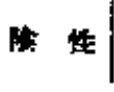 & 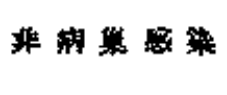 & 土 & - & - & - & \pm & - & - & - & + & - \\
\hline
\end{tabular}

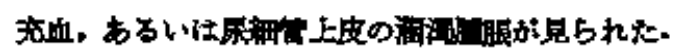

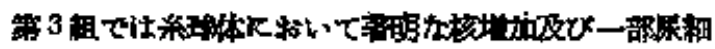

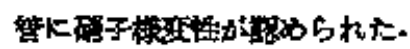

ii) 的作

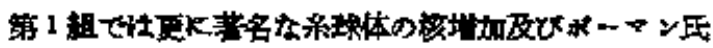

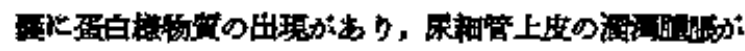
見られた.

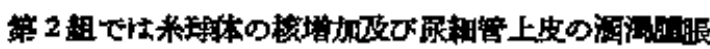

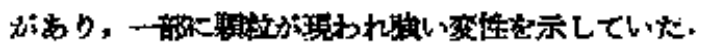

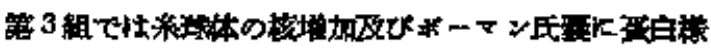

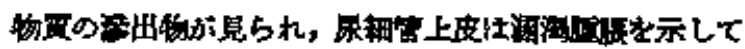
いた。

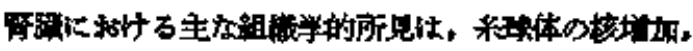

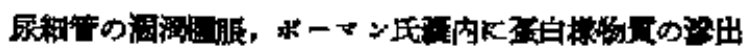

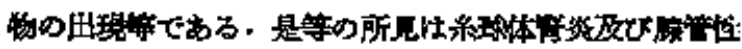
然奖煌有ないのでる。

\section{C. 小 括}

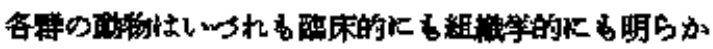

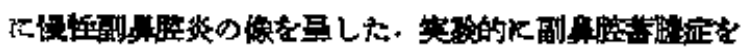

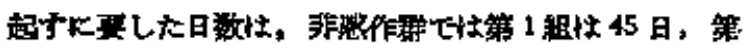

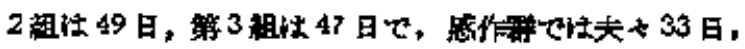

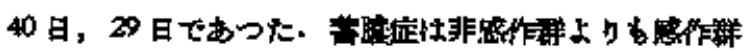

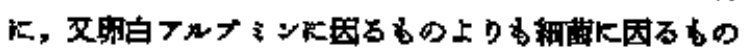
の方が早く発現した.

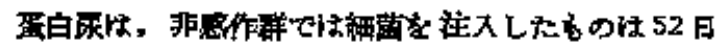

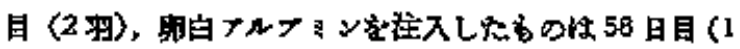

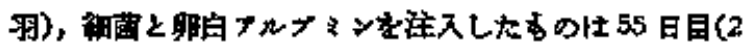

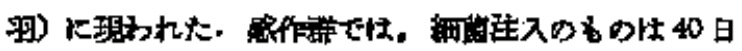

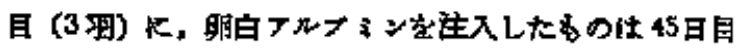

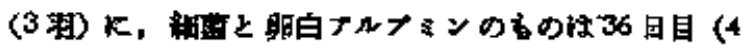

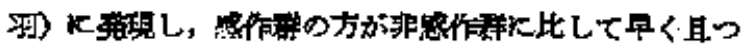

新例现われてくな。

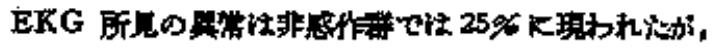

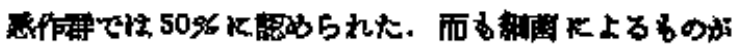

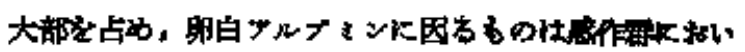

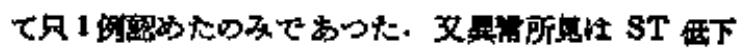

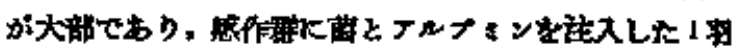
のみうう T 平低北であつた.

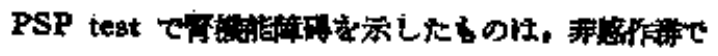

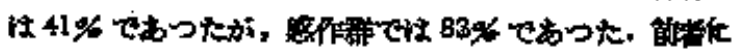

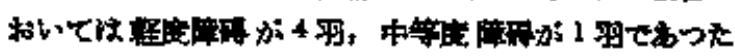

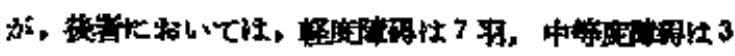

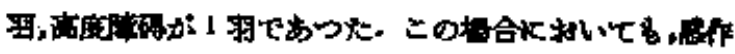

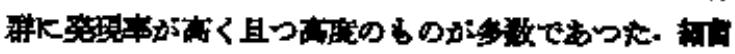

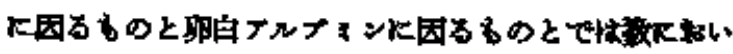

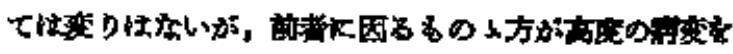

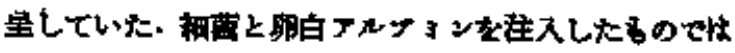

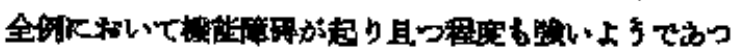

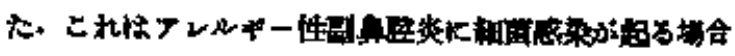

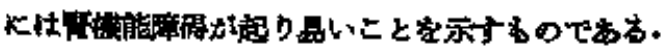

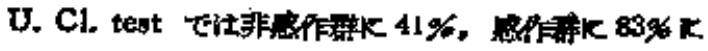

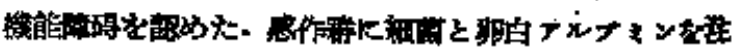

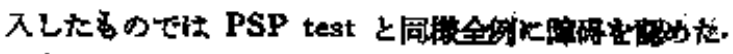

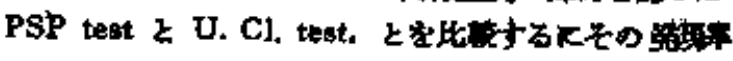

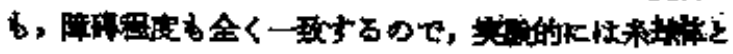

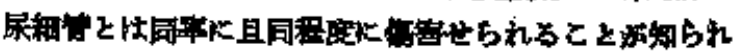

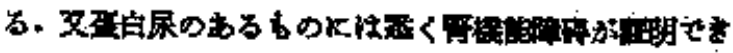

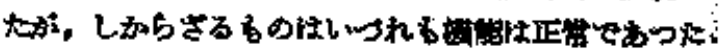

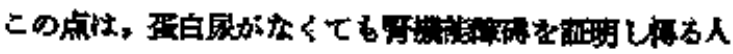

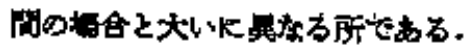

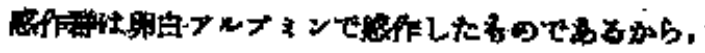

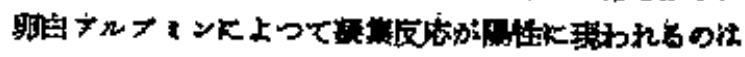




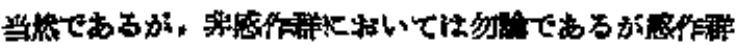

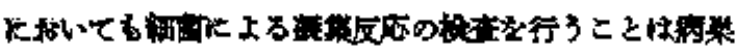

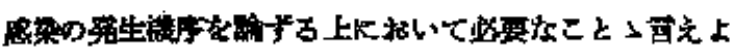
3 .

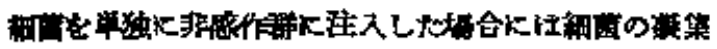

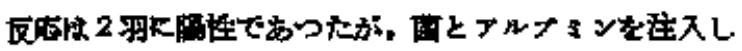

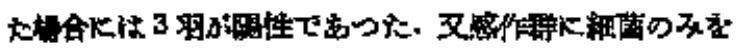

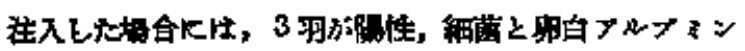

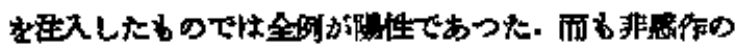

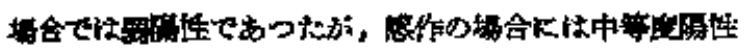

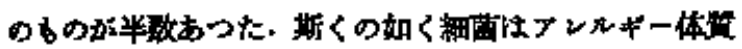

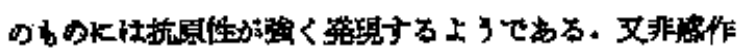

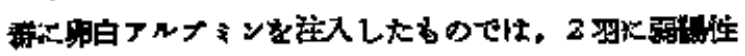

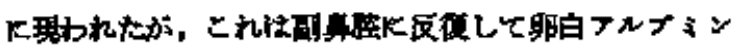

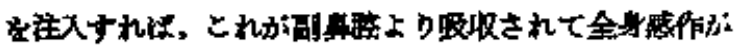

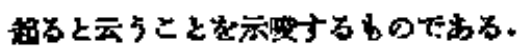

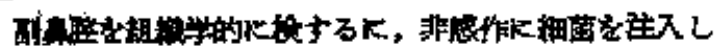

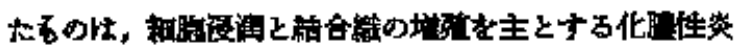

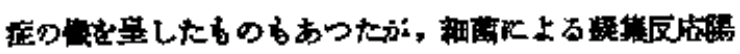

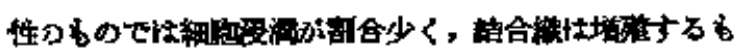

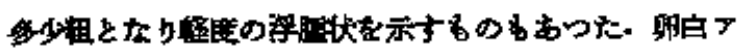

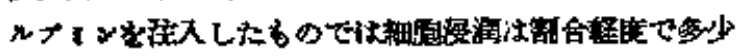

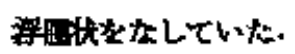

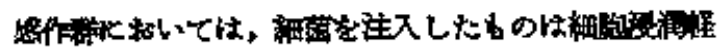

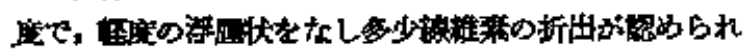

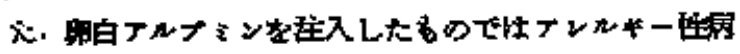

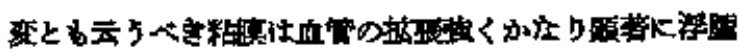

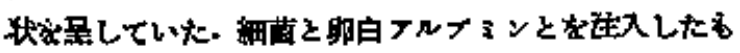

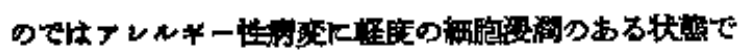
むつた.

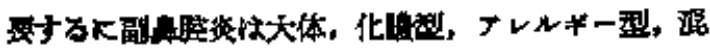

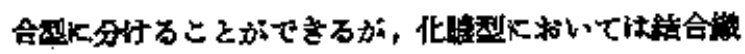

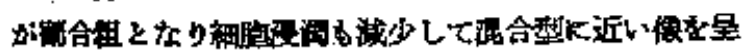

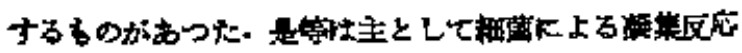

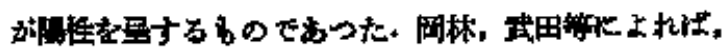

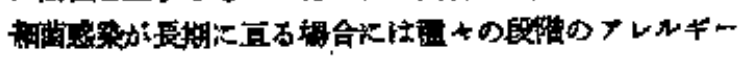

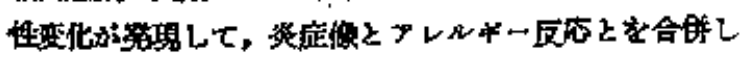

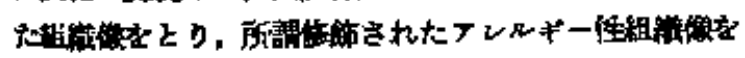

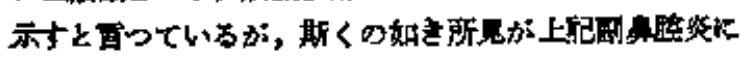
壮られふ.

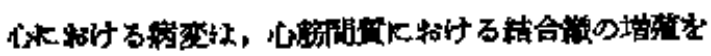

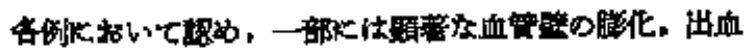

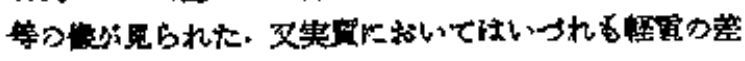

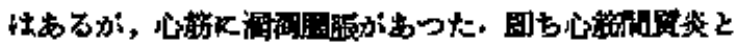

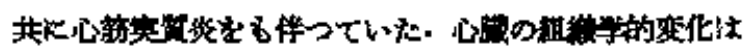
太体下机いて EKG の竞思と平行していた。

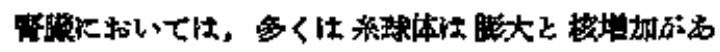

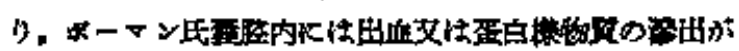

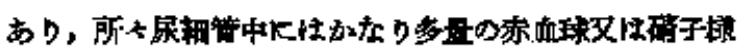

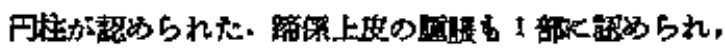

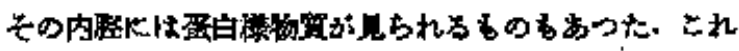

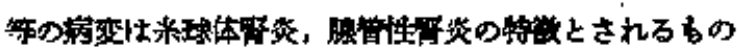

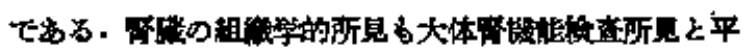
行Lた.

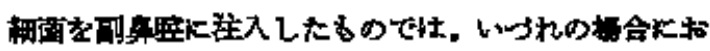

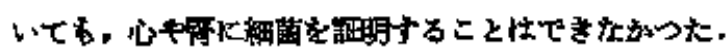

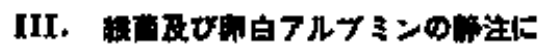

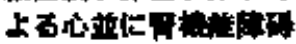

\section{A. 策的方洼}

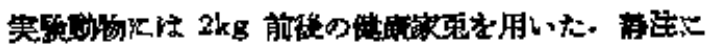

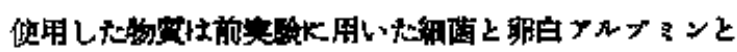

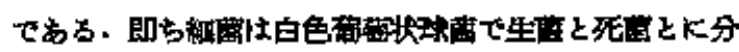

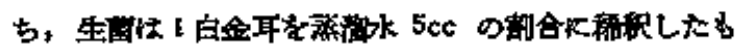

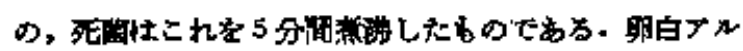

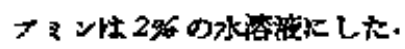

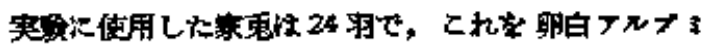

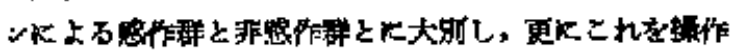

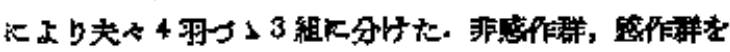

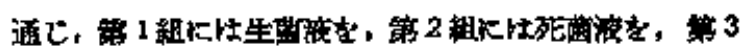

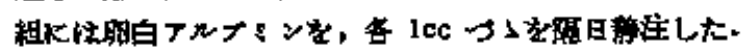

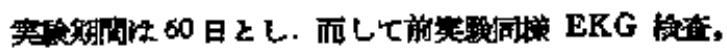

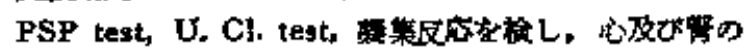

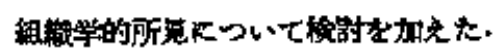

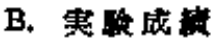

\section{1) EKG 所見}

由) 菲感作群

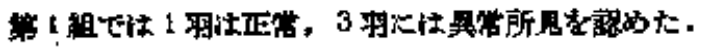

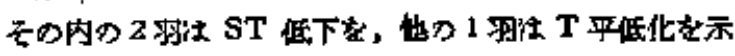

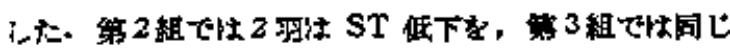

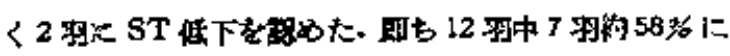

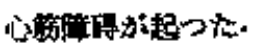

\section{b) 感作 群}

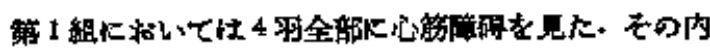

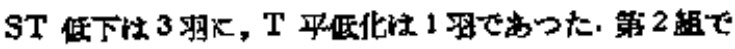

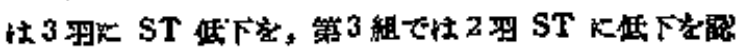

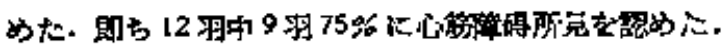




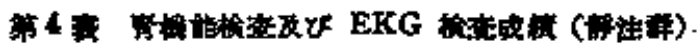

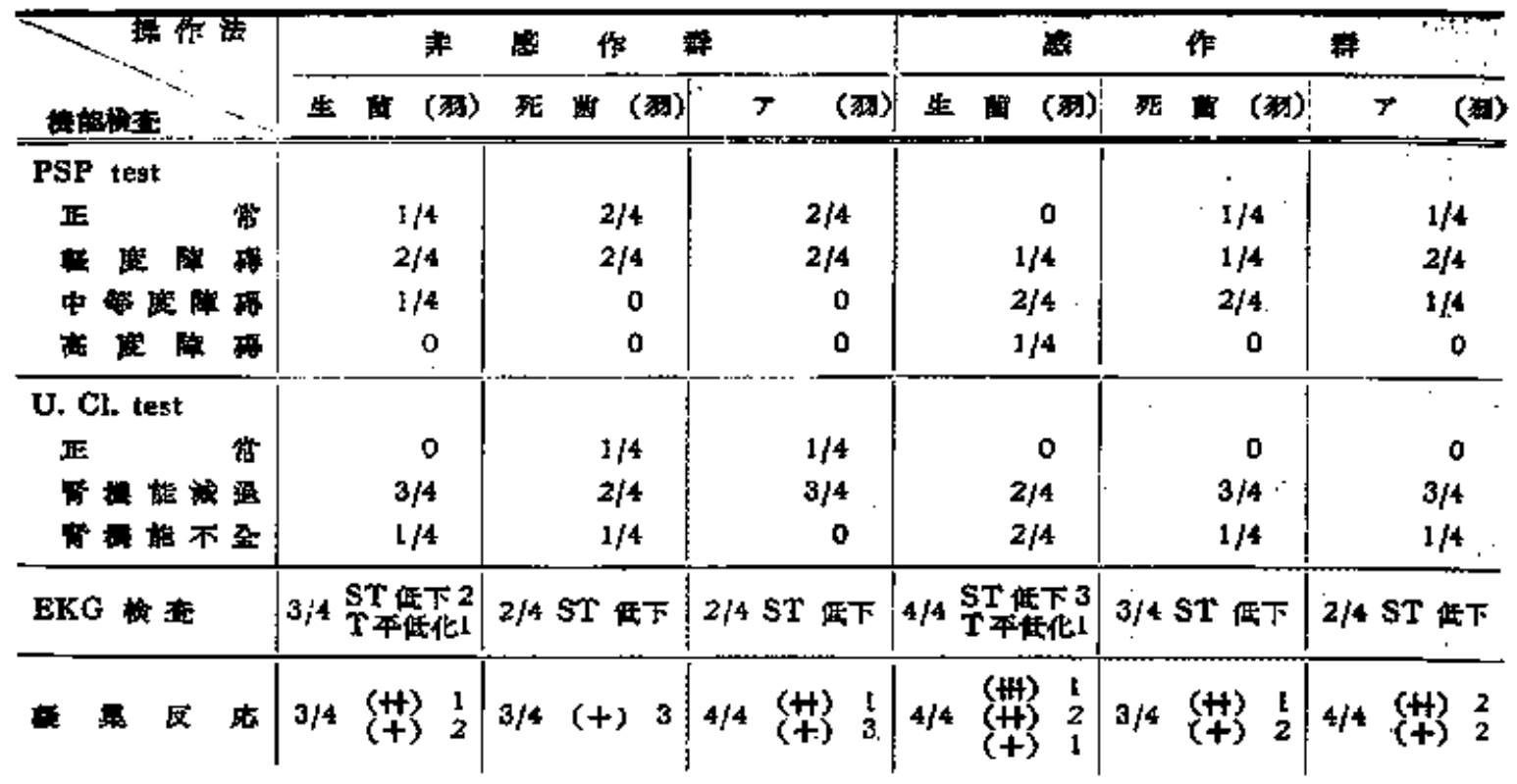

2) PSP test $O$ 所是

a) 非感作群

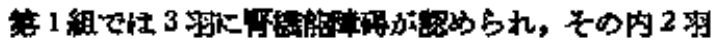

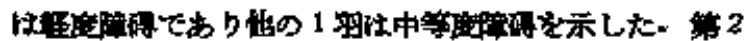

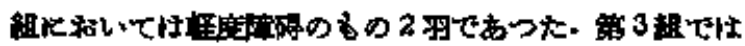

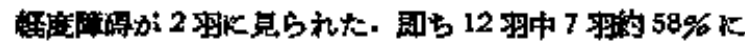

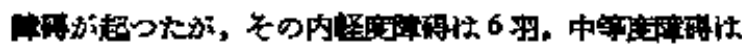
1 田とあった。

\section{b) 感作默}

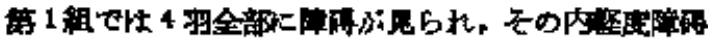

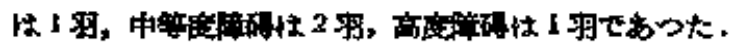

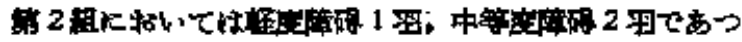

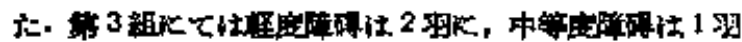

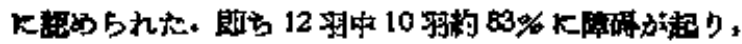

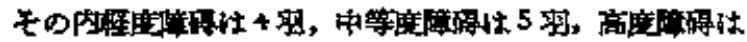

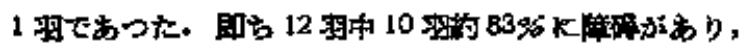

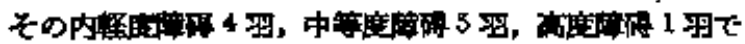
むつた.

3) U, Cl, test 所惫

a) 非为作夥

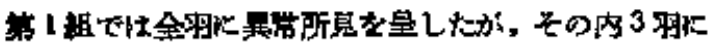

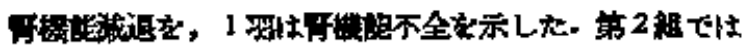

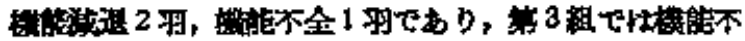

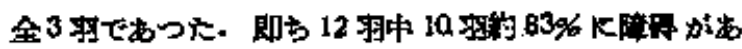

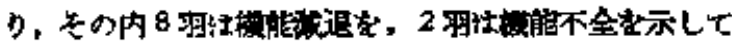

いた。

\section{b) 忽 $f$ 作}

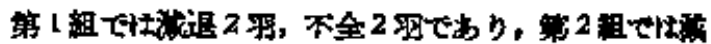

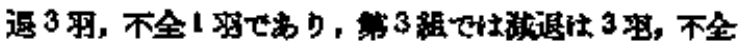

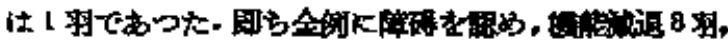

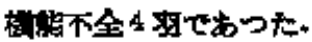

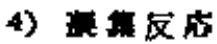

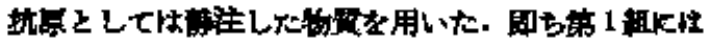

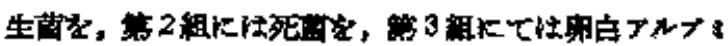

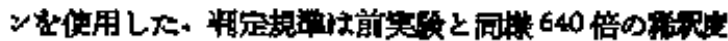

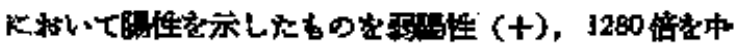

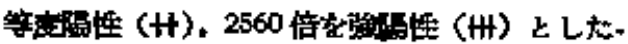

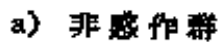

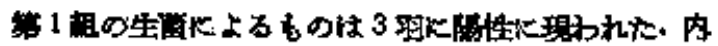

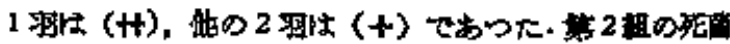

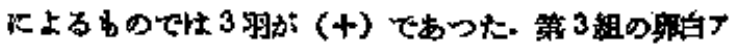

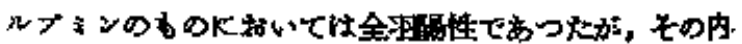
1 取忙 (H), 3 翼性 (十) でった。

\section{b) 船 作 群}

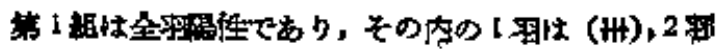

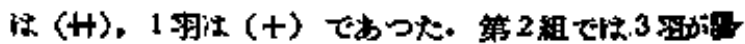

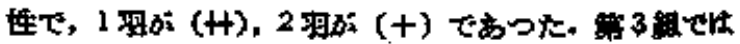

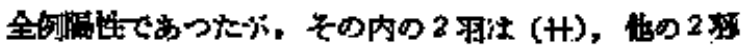
快 (+) ておつt. 


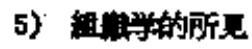
a) 心

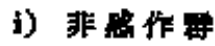

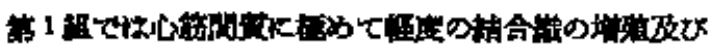

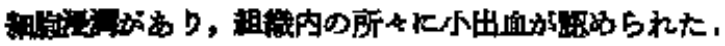

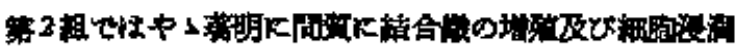

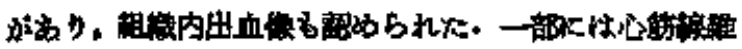

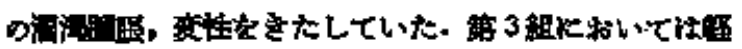

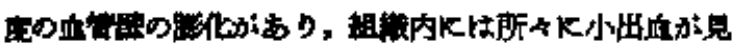
sht.

ii) 密作群

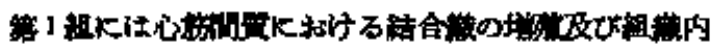

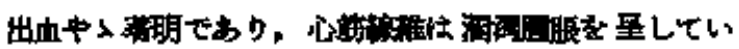

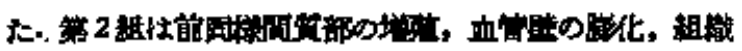

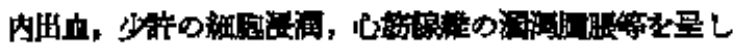

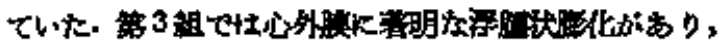

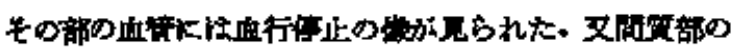

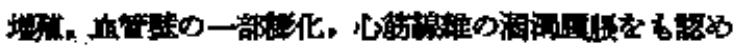

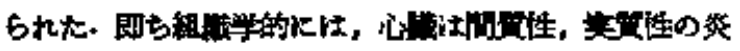

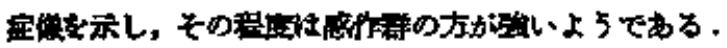

b) T

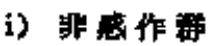

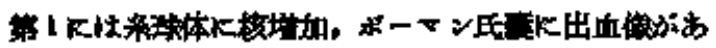

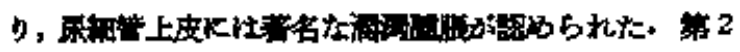

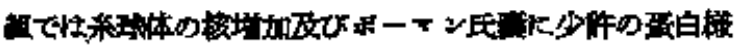

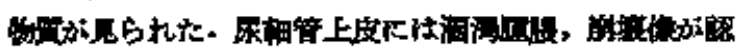

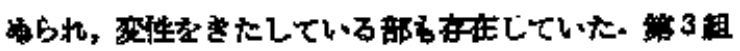

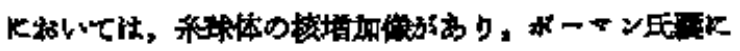

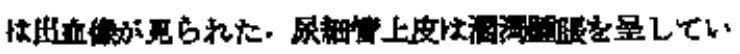
*.

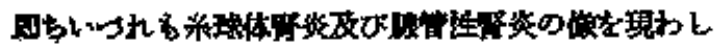
cht.

\section{ii). 蕊 作、群}

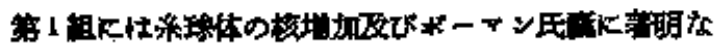

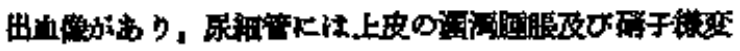

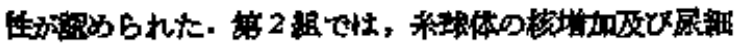

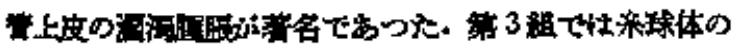

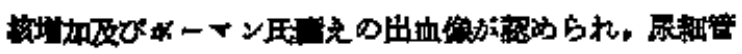

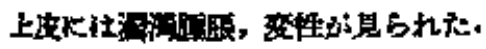

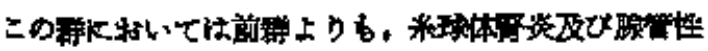

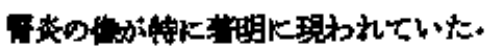

\section{: C. 小 括}

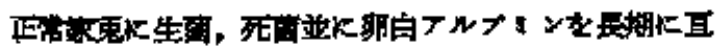

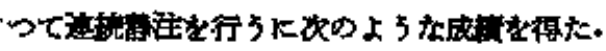

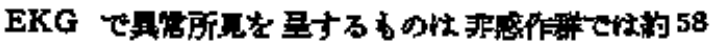

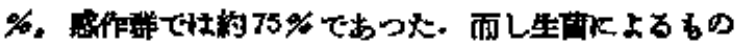

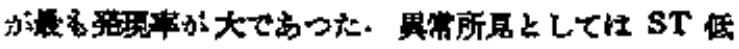

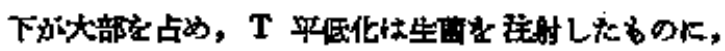

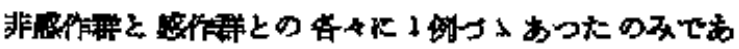
\$.

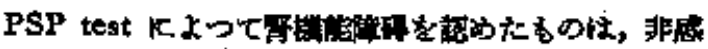

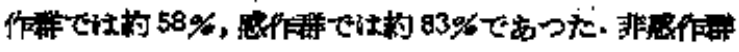

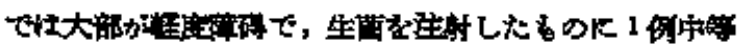

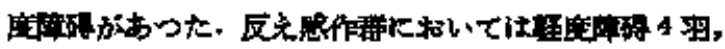

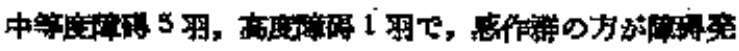

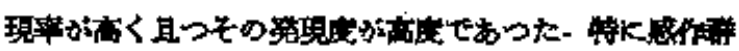

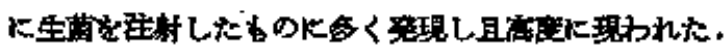

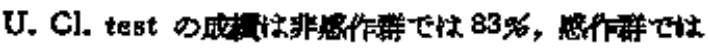

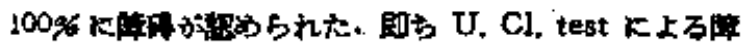

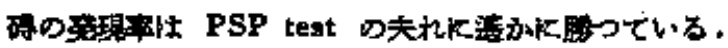

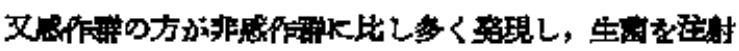

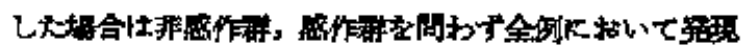

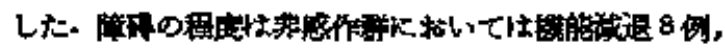

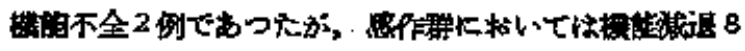

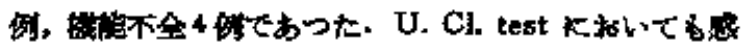

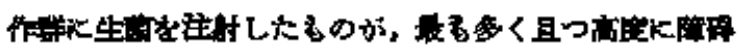
方琶われてい:。.

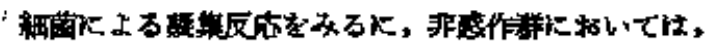

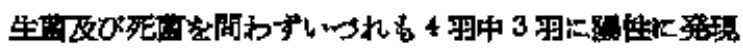

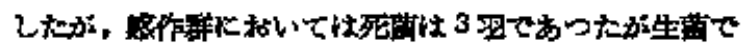

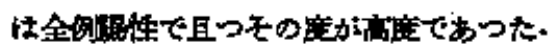

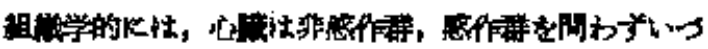

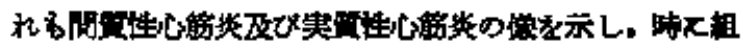

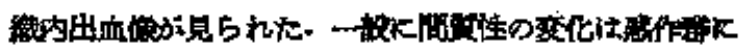

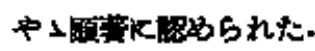

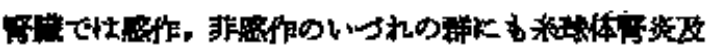

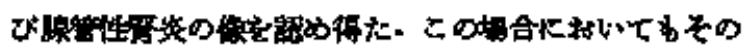

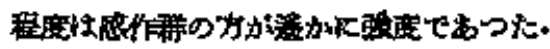

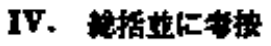

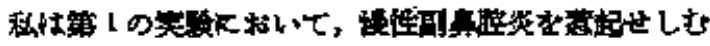

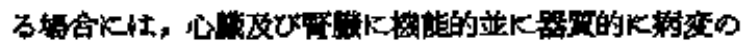

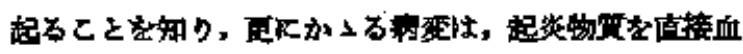

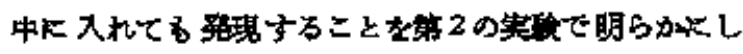

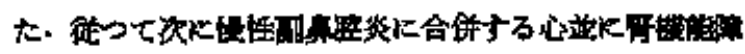

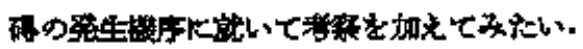

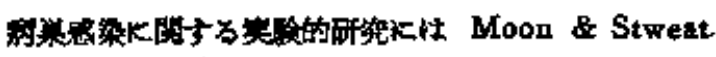




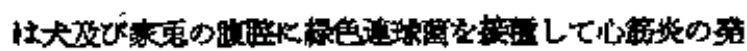

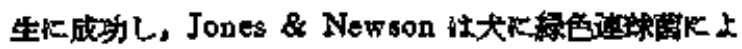

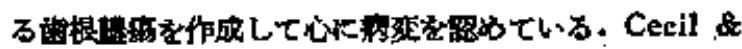

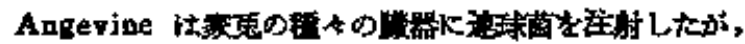

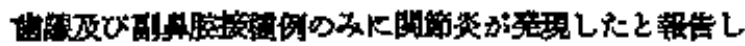

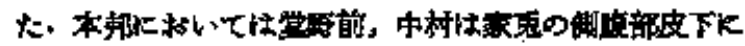

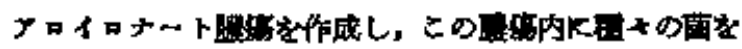

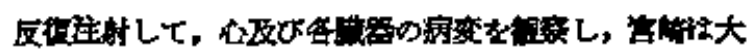

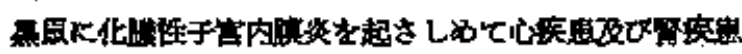

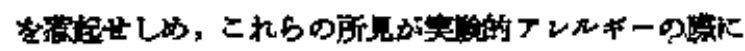

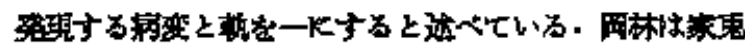

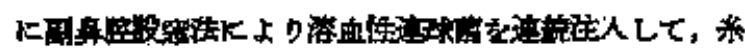

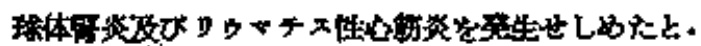

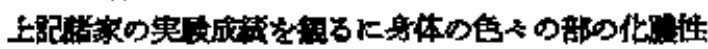

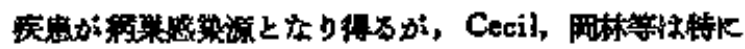

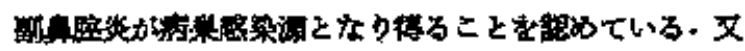

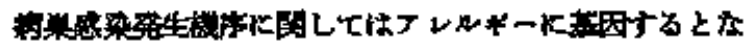

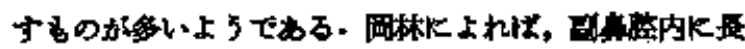

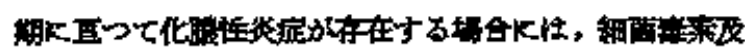

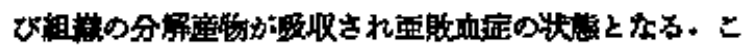

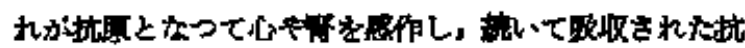

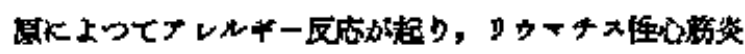

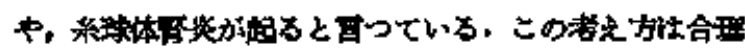

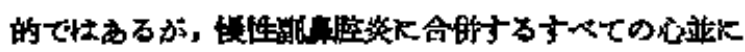

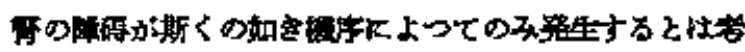
艺万机以.

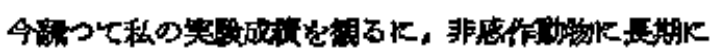

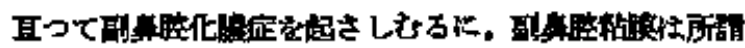

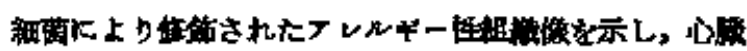

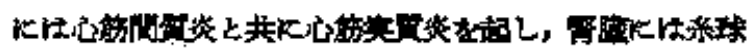

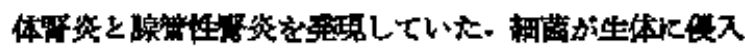

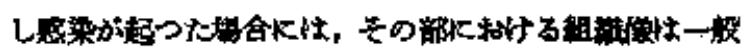

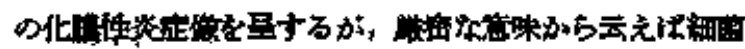

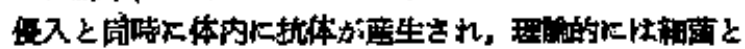

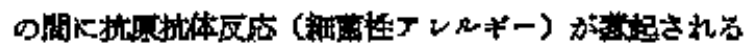

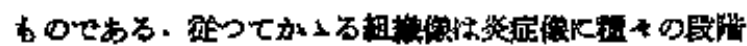

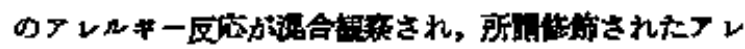

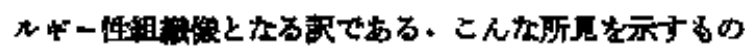

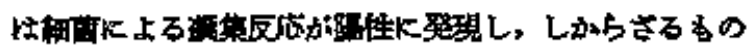

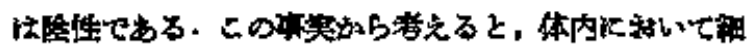

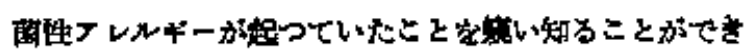

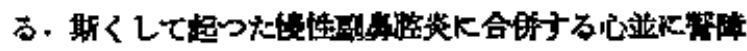

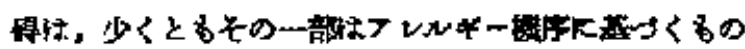

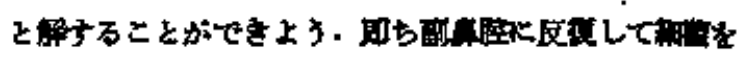

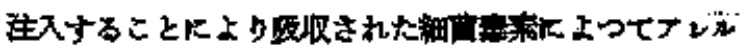

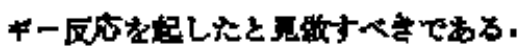

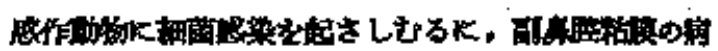

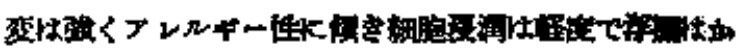

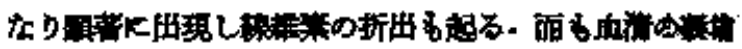

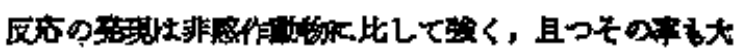

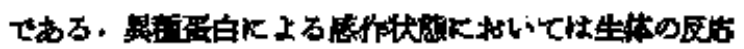

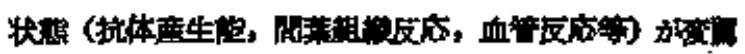

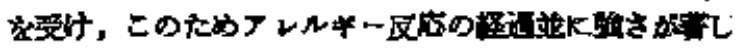

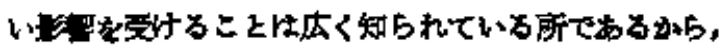

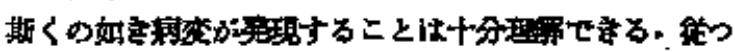

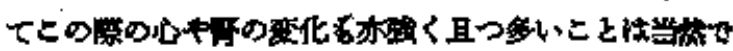

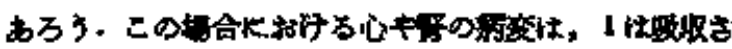

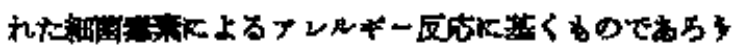

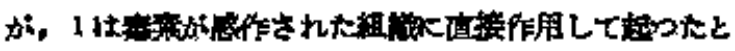

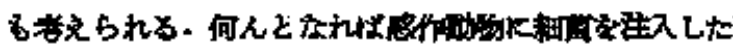

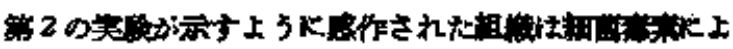

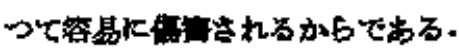

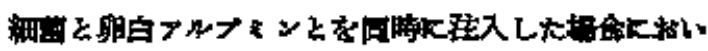

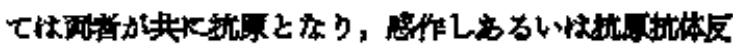

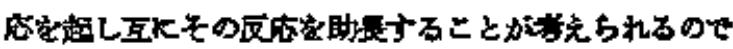

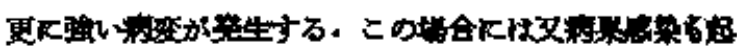

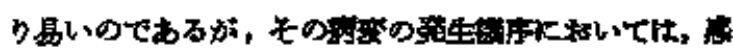

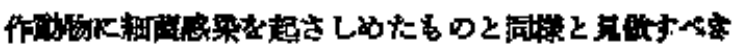
なまろっ -

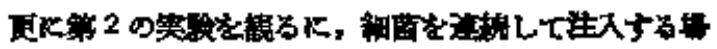

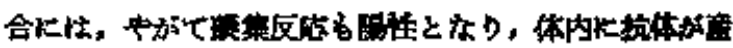

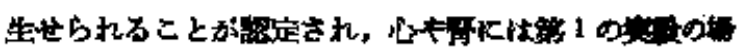

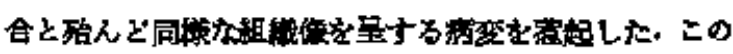

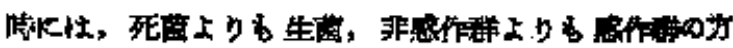

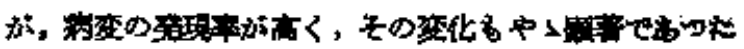

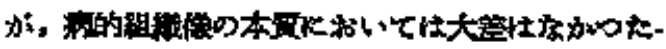

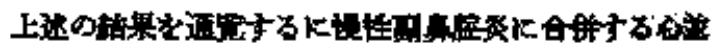

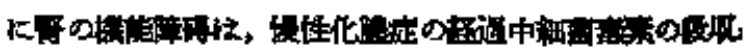

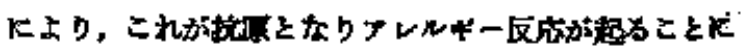

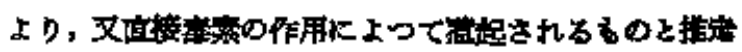

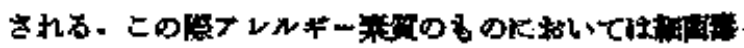

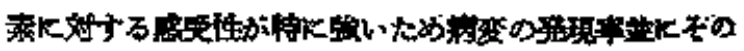

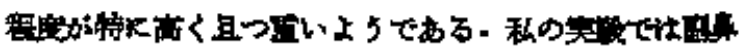

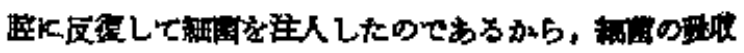

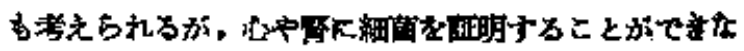

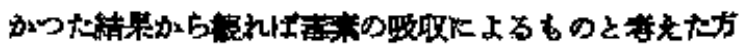




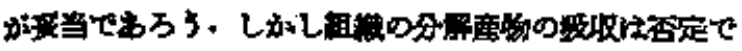

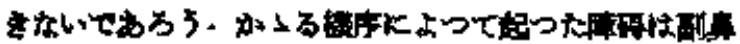

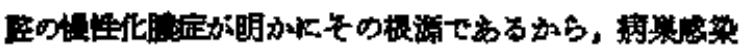

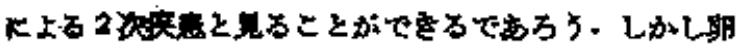

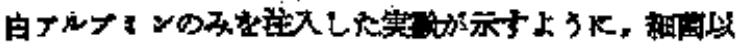

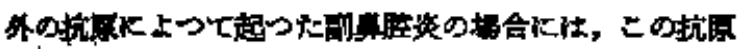

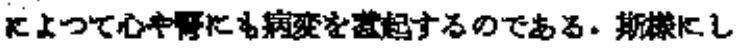

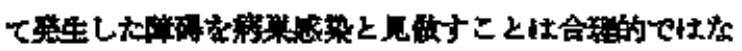

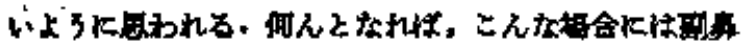

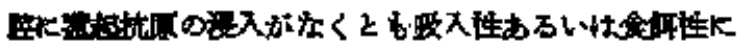

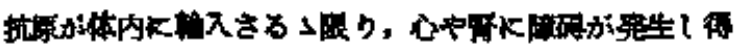

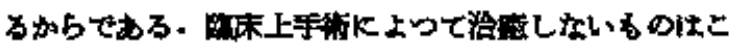

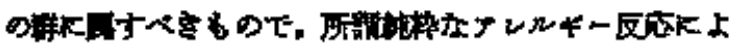

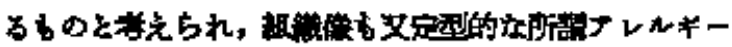

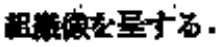

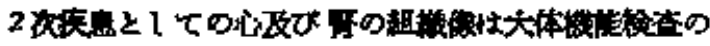

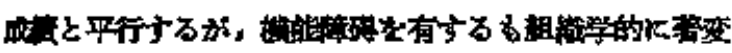

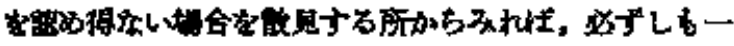

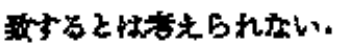

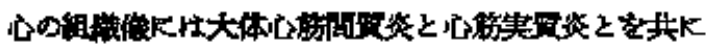

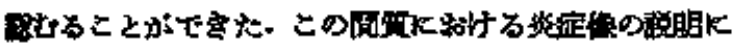

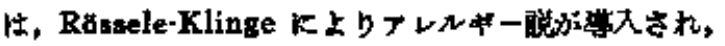

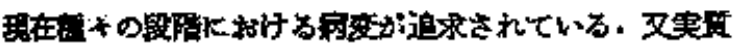

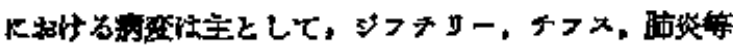

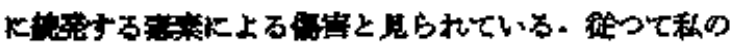

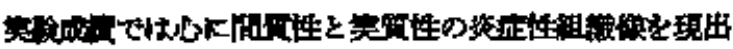

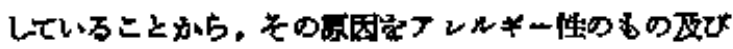

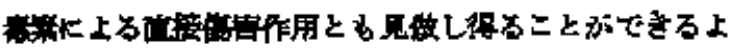
万人如。.

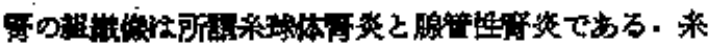

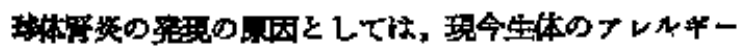

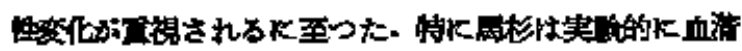

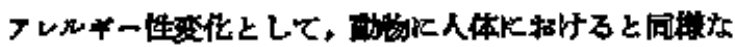

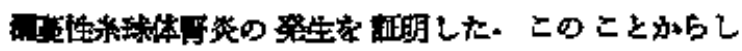

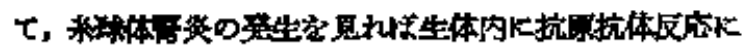

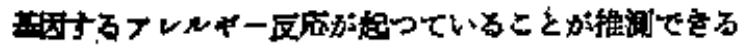

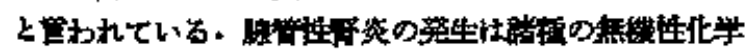

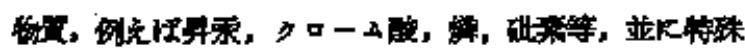

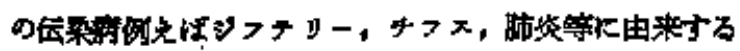

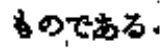

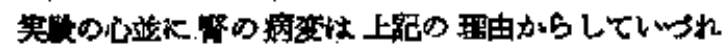

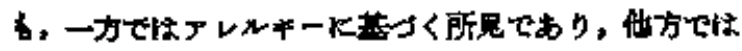

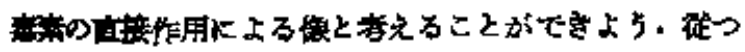

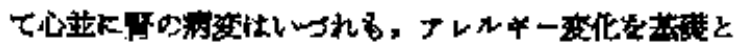

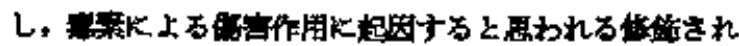

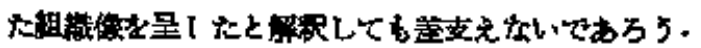

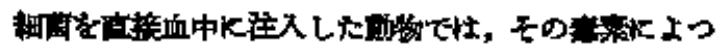

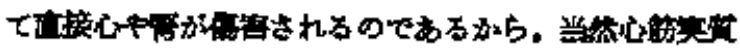

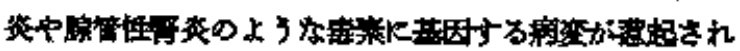

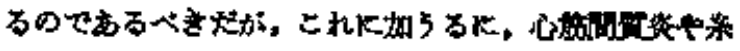

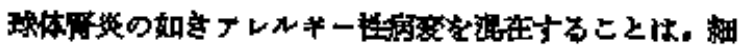

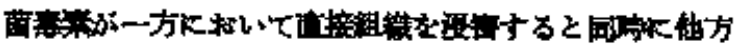

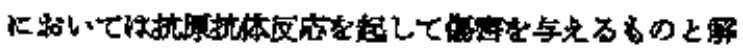

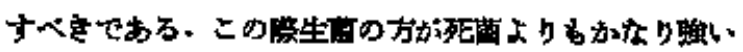

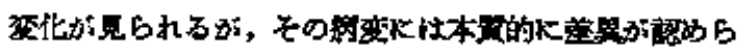

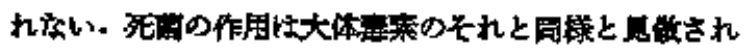

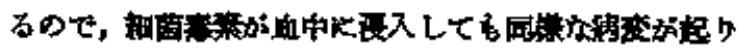

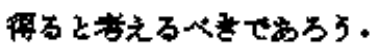

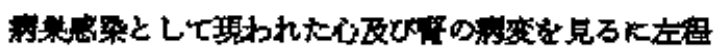

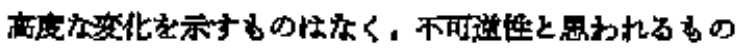

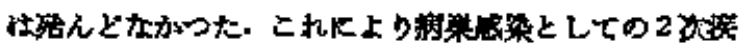

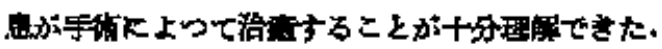

\section{v. 浾}

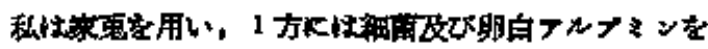

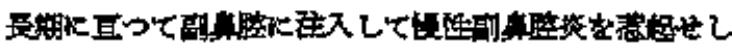

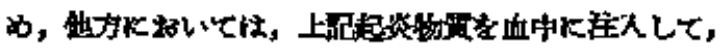

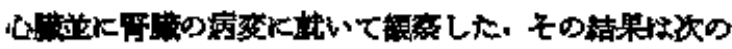
上万て市。

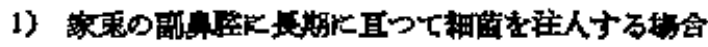

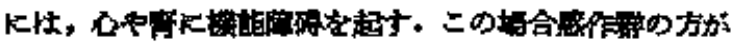

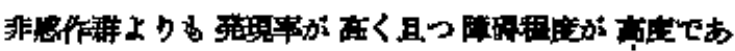

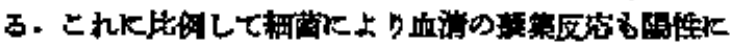

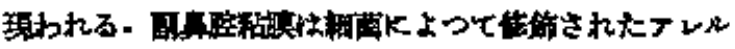

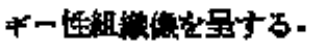

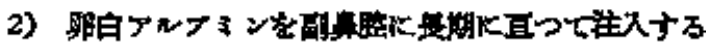

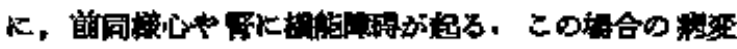

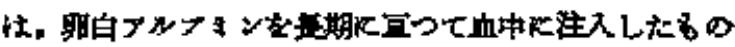

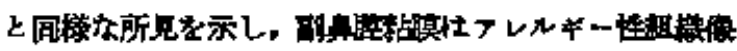
を뫃․

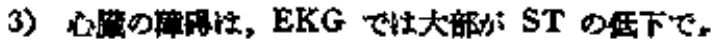

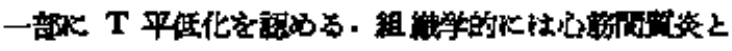

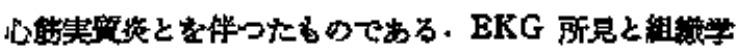
的所見と恃大体平行了る.

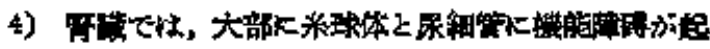

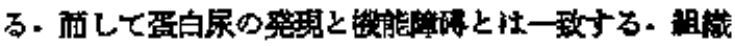

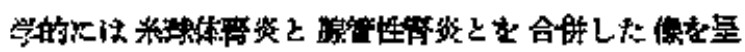




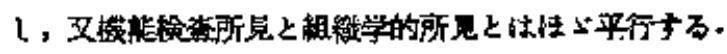

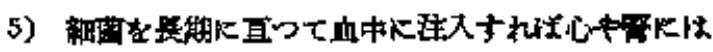

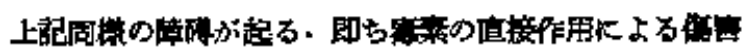

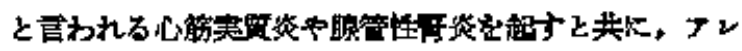

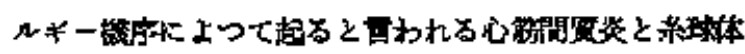

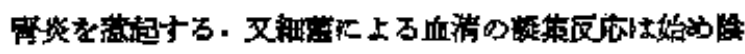
栍のすのか俻作珄となる。

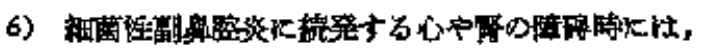

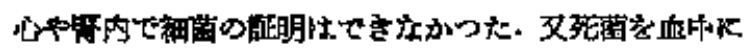

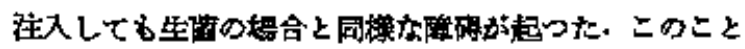

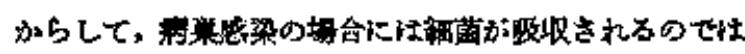

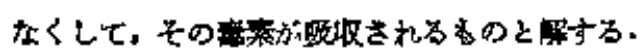

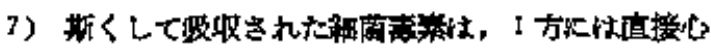

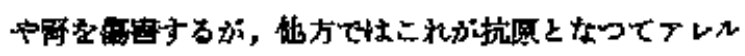

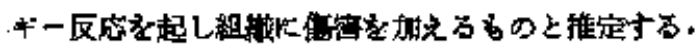

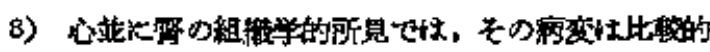

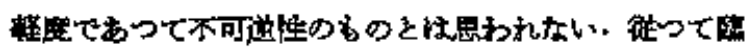

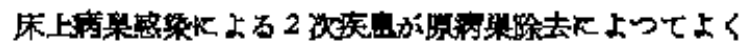

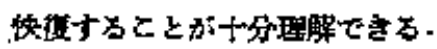

\section{主 文}

1) Päster: Verh. Dentвch. Geg. inn. Med., 321, 1909. 2) Billings: Arch. int. med., 9, 484, 1912. 3) Rosenow: ilid.. 408, 1930, 4) Mfom \& Stooeat: Arch. Path., 11, J90, 1931. 5) Dietrich, W.: Virchow Arch., 299, 255, 1937, 6) Gutreit 2. Parads: Ergeb. inn. med. u. Kind., 57, 1939. 7) Wolcher: Verh. Deutsch. Ges. inn. Med, 5I, 1939. 8) Marphy, G.E. \& Suoff, H,F.: J. Exp. Med., 91, 485, 1950. 9) Frederick, C.: Arch.

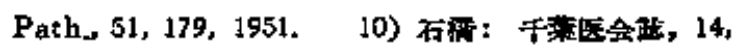

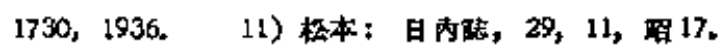

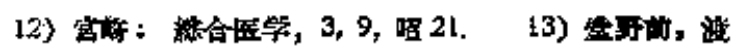

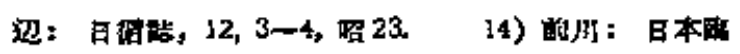

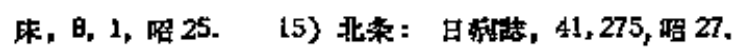
16)面林：免没

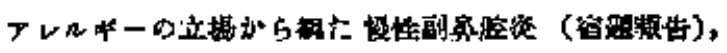
喕 32 .

\section{制 囷些 明}

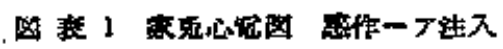

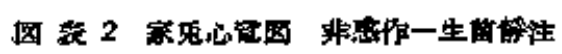

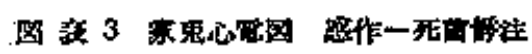

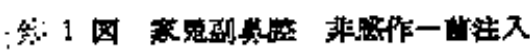

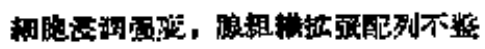

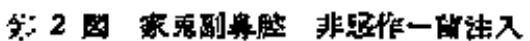

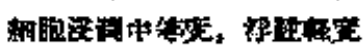

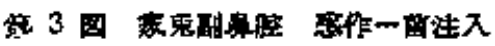

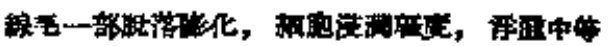

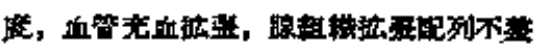

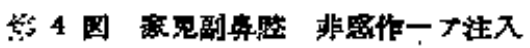

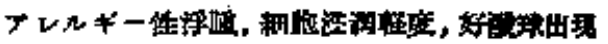

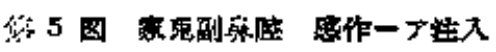

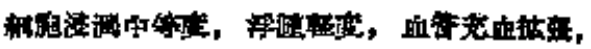
䧀酸大量出现

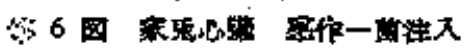

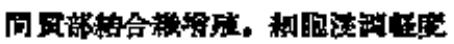

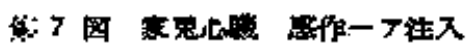

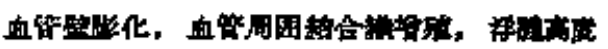

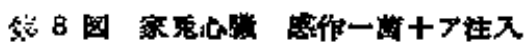

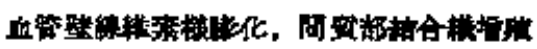

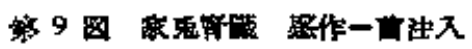

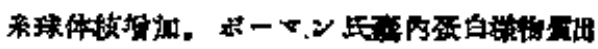

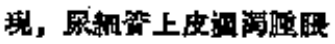

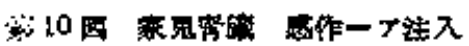

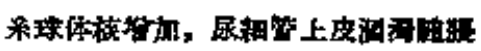

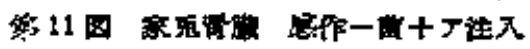

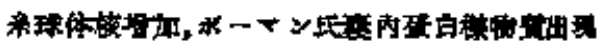

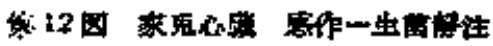

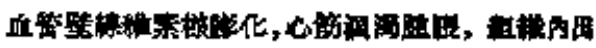
蛙

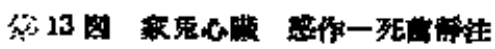

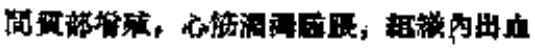

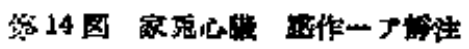
心外化化，血行本止

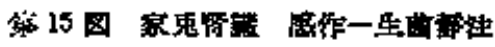

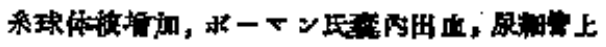

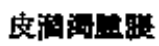

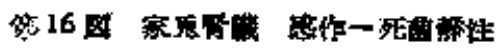

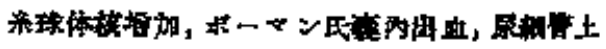

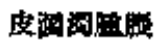

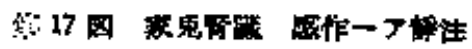

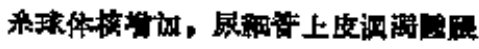

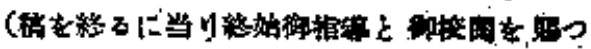

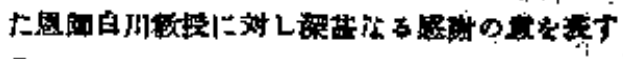
3.

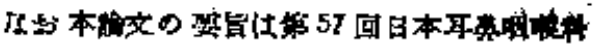

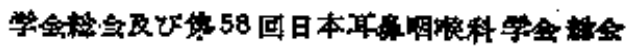

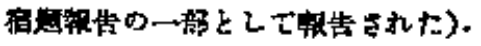

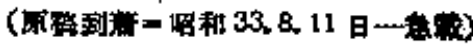


図表 1

家兔心電回N.166

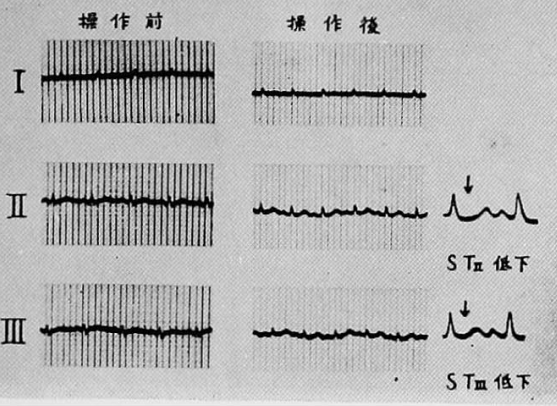

图表 2

家兔心電龱No62

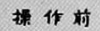

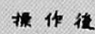

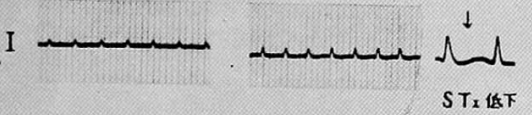

II

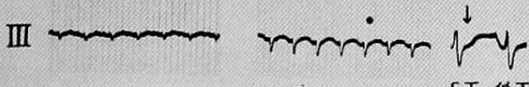

园表 3

家鬼心電图N 85

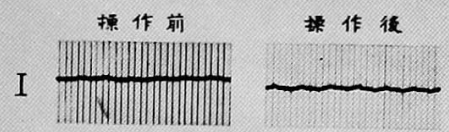

II 7 IIIIIIIIIII

$S T_{\text {I }}$ 低T

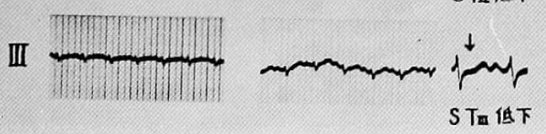

第 1 図

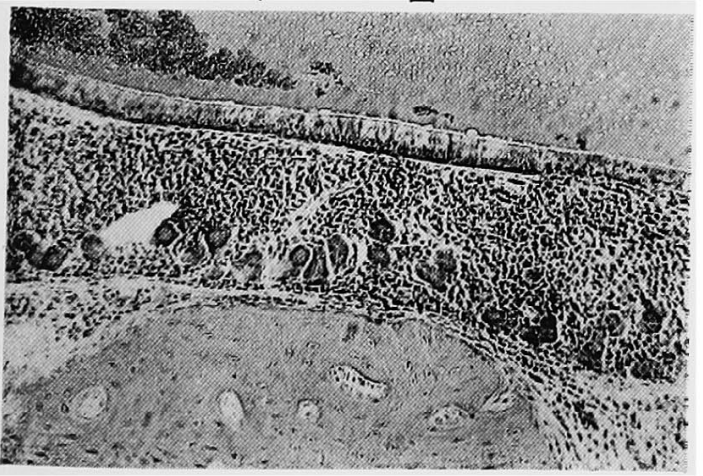

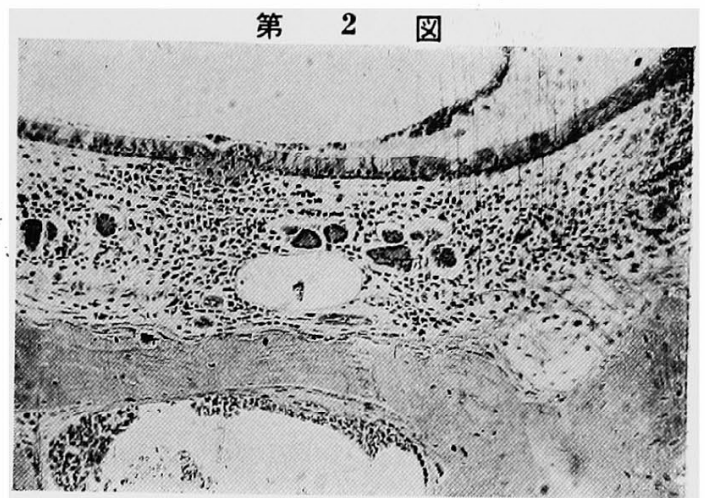

第 3 図

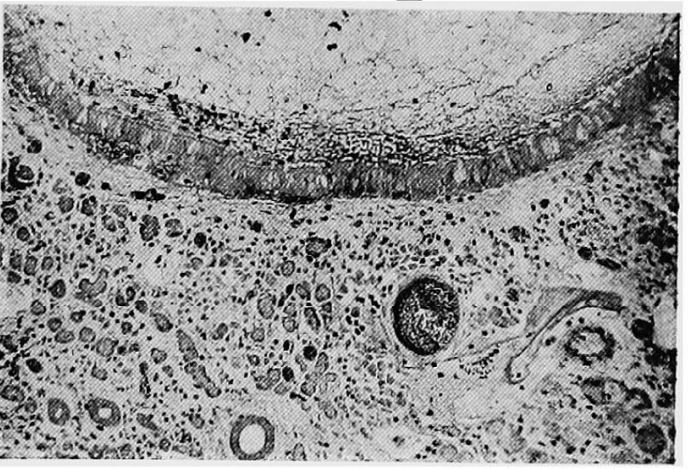

第 4 図

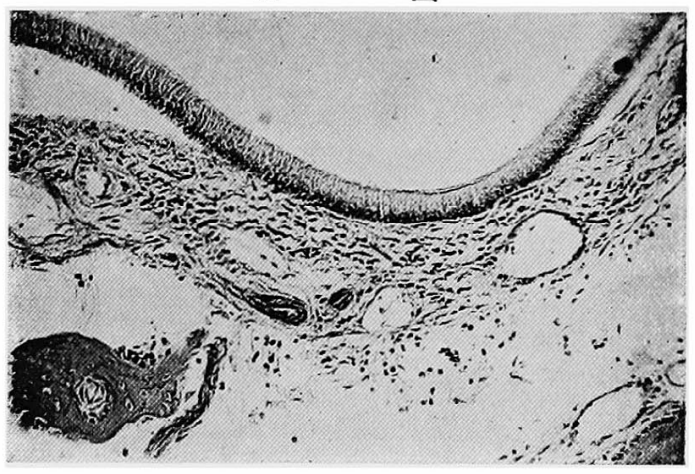

第 5 図

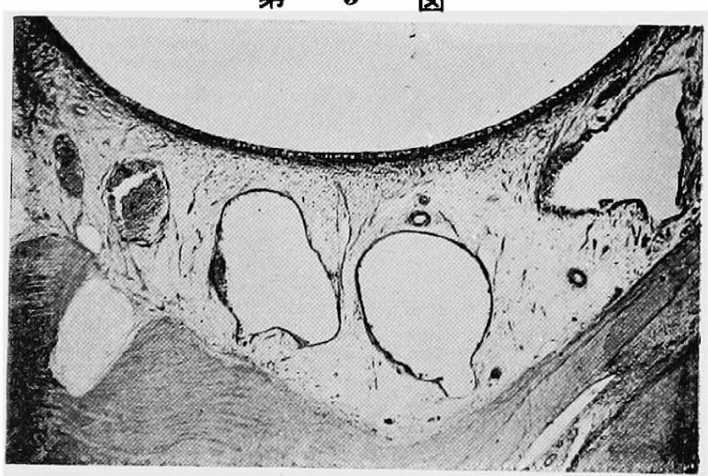


第 6 図

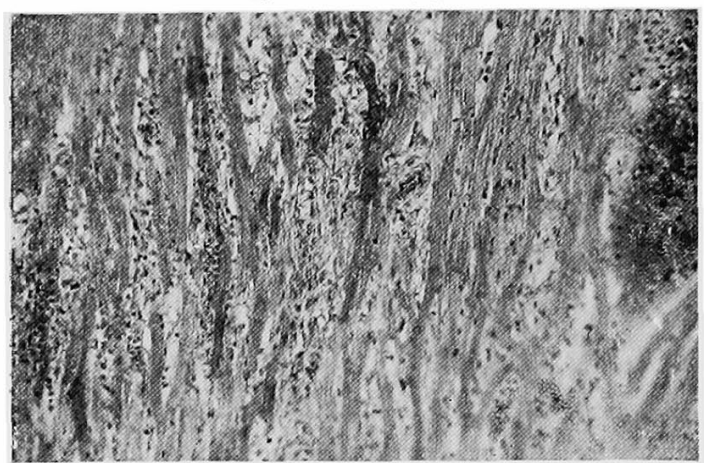

第 7 図

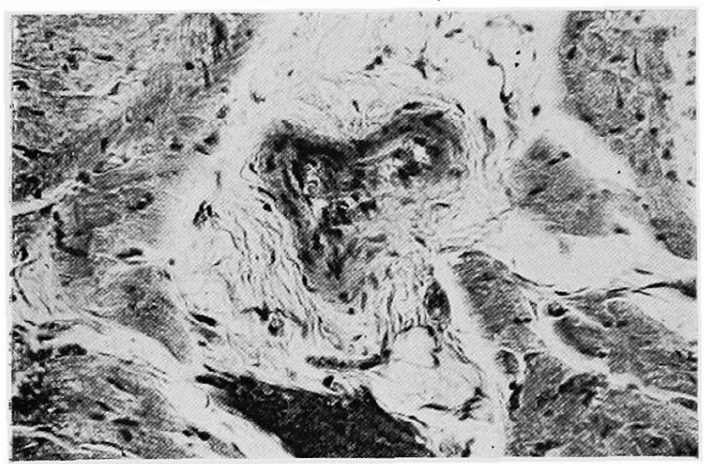

第 8 图

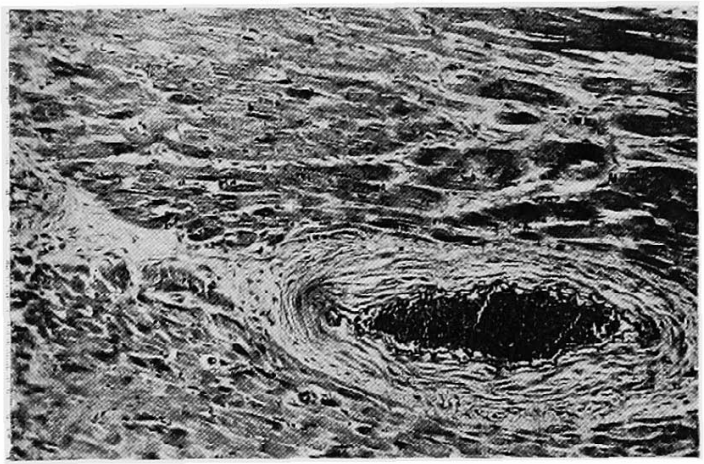

第 9 図

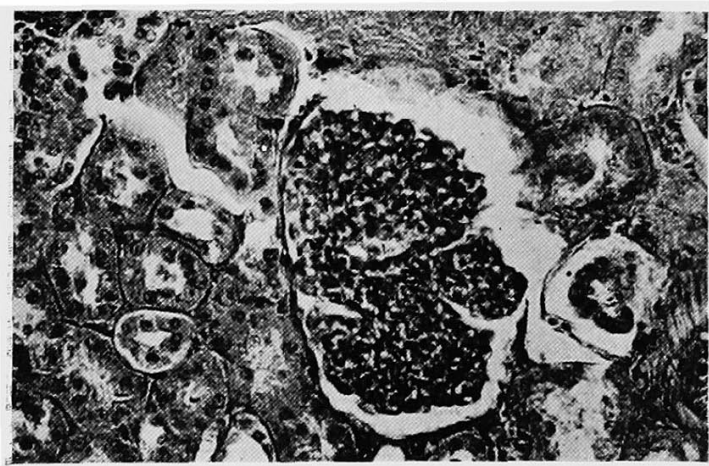

第 10 図

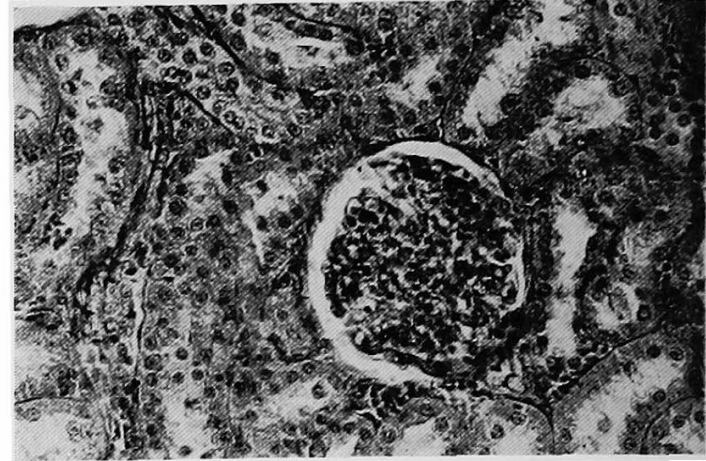

第 11 図
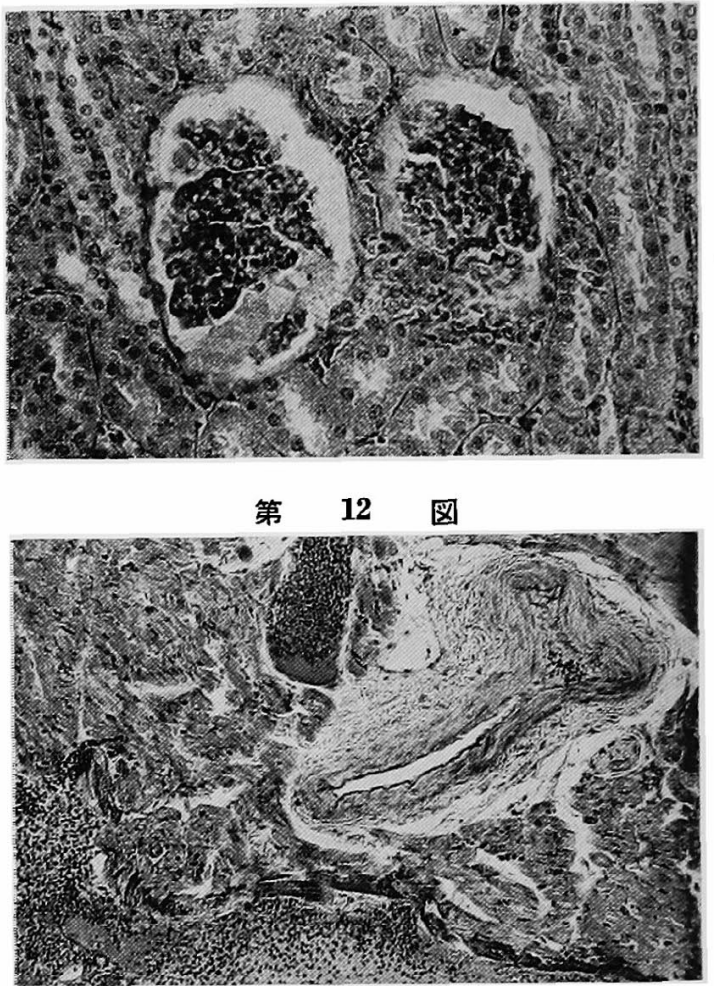

第 13 図

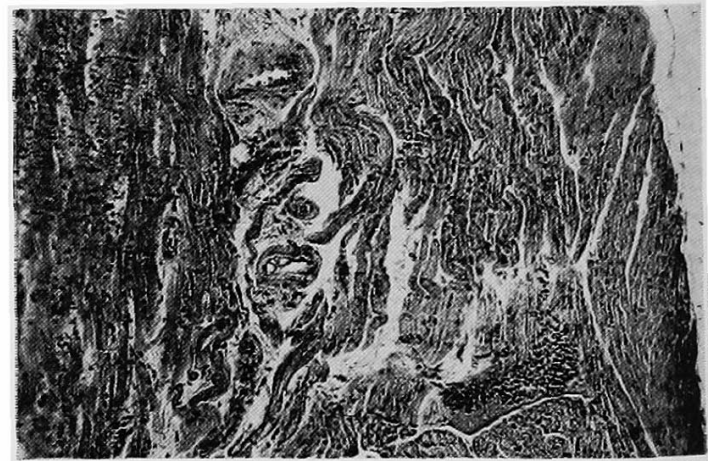


布村論文附図（III)
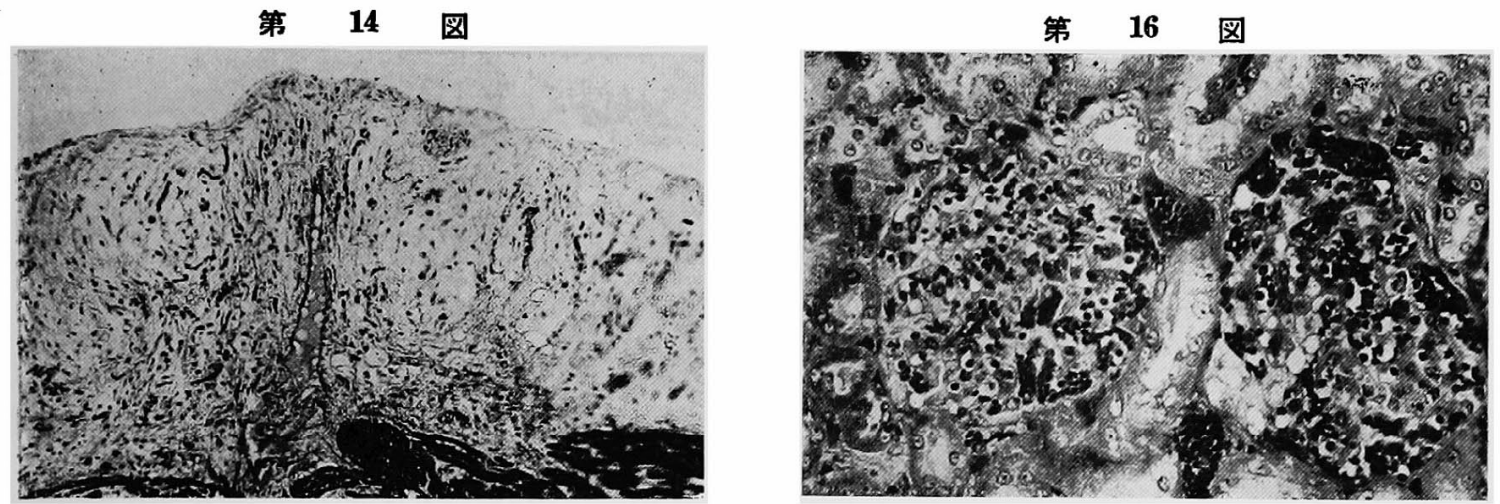

第 15 図
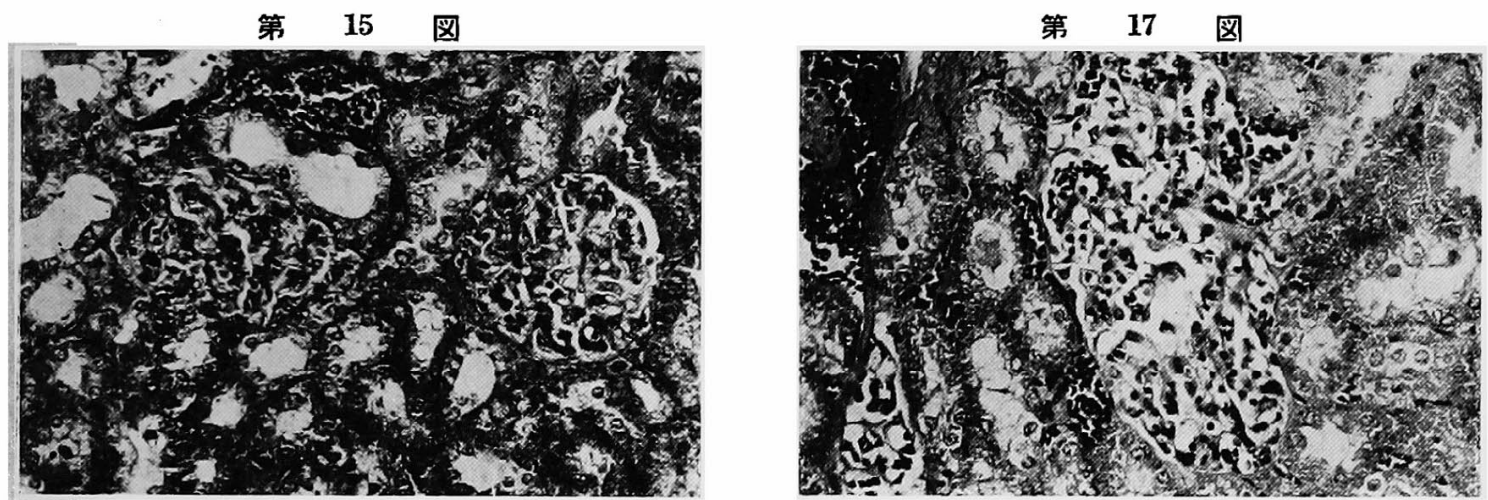